\title{
Elevated CD26 Expression by Skin Fibroblasts Distinguishes a Profibrotic Phenotype Involved in Scar Formation Compared to Gingival Fibroblasts
}

\author{
Wesley Mah, ${ }^{\star}$ Guoqiao Jiang, ${ }^{*}$ Dylan Olver, ${ }^{*}$ Corrie Gallant-Behm, ${ }^{\dagger}$ Colin Wiebe, ${ }^{\star}$ David A. Hart,${ }^{\ddagger}$ Leeni Koivisto, ${ }^{*}$ \\ Hannu Larjava,* and Lari Häkkinen*
}

From the Department of Oral Biological and Medical Sciences, * Faculty of Dentistry, University of British Columbia, Vancouver, British Columbia, Canada; miRagen Therapeutics, Inc., ${ }^{\dagger}$ Boulder, Colorado; and the Department of Surgery, ${ }^{\ddagger}$ McCaig Institute for Bone and Joint Health, University of Calgary, Calgary, Alberta, Canada

\author{
Accepted for publication \\ April 6, 2017. \\ Address correspondence to \\ Lari Häkkinen, D.D.S., Ph.D., \\ Department of Oral Biological \\ and Medical Sciences, Faculty \\ of Dentistry, University of \\ British Columbia, 2199 Wes- \\ brook Mall, Vancouver, BC, \\ Canada V6T 1Z3. E-mail: \\ lhakkine@dentistry.ubc.ca.
}

\begin{abstract}
Compared to skin, wound healing in oral mucosa is faster and produces less scarring, but the mechanisms involved are incompletely understood. Studies in mice have linked high expression of CD26 to a profibrotic fibroblast phenotype, but this has not been tested in models more relevant for humans. We hypothesized that CD26 is highly expressed by human skin fibroblasts (SFBLs), and this associates with a profibrotic phenotype distinct from gingival fibroblasts (GFBLs). We compared CD26 expression in human gingiva and skin and in gingival and hypertrophic-like scar-forming skin wound healing in a pig model, and used three-dimensional cultures of human GFBLs and SFBLs. In both humans and pigs, nonwounded skin contained abundantly CD26-positive fibroblasts, whereas in gingiva they were rare. During skin wound healing, CD26-positive cells accumulated over time and persisted in forming hypertrophic-like scars, whereas few CD26-positive cells were present in the regenerated gingival wounds. Cultured human SFBLs displayed significantly higher levels of CD26 than GFBLs. This was associated with an increased expression of profibrotic genes and transforming growth factor- $\beta$ signaling in SFBLs. The profibrotic phenotype of SFBLs partially depended on expression of CD26, but was independent of its catalytic activity. Thus, a CD26-positive fibroblast population that is abundant in human skin but not in gingiva may drive the profibrotic response leading to excessive scarring. (Am J Pathol 2017, 187: 1717-1735; http://dx.doi.org/10.1016/j.ajpath.2017.04.017)
\end{abstract}

Wound-healing problems in skin include slowly healing or nonhealing chronic wounds and excessive (pathological) scar formation (hypertrophic scars and keloids) and are a major burden for millions of patients and to society. Currently, no predictably effective treatment for these problems exists, emphasizing the need to better understand these processes. ${ }^{1-4}$ Studies from human and animal models have shown that wound healing in oral mucosa is markedly faster and results in significantly reduced scar formation compared to skin. ${ }^{5-12}$ The reasons for the better wound healing in oral mucosa are not completely understood, but may depend on different fibroblast populations residing in the tissues.

Fibroblasts are a heterogeneous group of connective tissue cells that are key effectors in wound healing and scar formation as they generate the extracellular matrix (ECM) niche that guides connective tissue repair and restores ECM structure and function. Fibroblasts also participate in regulation of inflammation, angiogenesis, and reepithelialization. ${ }^{3,13-16}$ Partly because of lack of specific markers to identify fibroblast subsets, they have remained relatively poorly understood regarding their developmental

\footnotetext{
Supported by Canadian Institutes of Health Research (CIHR) grants MOP 77550 (L.H.) and PJT-153223 (L.H.), a Natural Sciences and Engineering Research Council of Canada (NSERC) grant (L.H.), the University of British Columbia (UBC) CIHR Skin Research Training Center Award (W.M.), the UBC Dentistry Undergraduate Student Summer Research Awards (D.O.), and the Osteology Foundation (L.H.).

Disclosures: C.G.-B. is a full-time employee and holds stock options for miRagen Therapeutics, Inc.
} 
origins, lineage characteristics, and specific functions. ${ }^{4,16}$ It is becoming clear that the properties of fibroblast populations residing in a given tissue and recruited to the wound site may determine the wound-healing outcome. For instance, populations associated with hair follicles, in papillary dermis, and in deeper layers of skin differently contribute to pathological scarring. ${ }^{17}$ Consequently, hypertrophic scar-derived cell populations display a profibrotic phenotype distinct from cells that predominate in the normal tissue. ${ }^{18}$ Interestingly, fibroblasts in skin and oral mucosa also have distinct properties. ${ }^{11,12,16-26}$ For instance, oral mucosal fibroblasts share certain properties with fetal skin cells, which drive the fast and scarless healing in fetal skin, but that are distinct from adult skin fibroblasts. ${ }^{11,21,22,25-29}$ Studies using oral mucosal gingival fibroblasts in experimental therapy in vivo have also suggested that they have distinct regenerative potential over skin cells. ${ }^{25,30}$

The phenotypic traits of fibroblasts found in different tissues and tissue compartments may be cell intrinsic and/or depend on the local tissue niche. ${ }^{18,31,32}$ This niche is qualitatively and quantitatively different (eg, in gingiva and skin). ${ }^{29}$ However, although oral mucosal and skin cells display distinct gene expression profiles in vivo, they remain also different in vitro, $, 12,26,33-35$ suggesting that these properties can also be cell intrinsic. Some of these intrinsic properties may originate during development, as fibroblasts in different body locations derive from different germ layers. Most connective tissue cells in the oral cavity, including gingiva, and facial skin arise from the neural crest, whereas skin fibroblasts in other body locations are predominantly from the mesoderm. ${ }^{12,18,25,36-38}$ More important, functionally distinct fibroblast subpopulations retain their developmentally imprinted gene expression profiles in adult tissues. ${ }^{12,24,33,39,40}$ For instance, different skin fibroblast subpopulations that can be identified based on expression of certain surface markers produce papillary and deeper reticular and hypodermal fibroblast lineages, respectively. In adult mice, the reticular lineage can be characterized by coexpression of cell surface markers, stem cell antigen-1 and CD26 [dipeptidyl peptidase-4 (DPP4)], a type II transmembrane glycoprotein with multiple enzymatic and nonenzymatic functions. ${ }^{41-43}$ This population composed $70 \%$ to $80 \%$ of the fibroblasts in the skin and participated in wound healing by producing the bulk of fibrillar ECM. In contrast, a different fibroblast population in papillary dermis negative for stem cell antigen-1 but positive for leucine-rich repeats and immunoglobulin-like domains 1 surface marker participated in hair follicle formation and reepithelialization. ${ }^{24,44}$ In another study, two fibroblast subpopulations derived from embryonic mesodermal fibroblast progenitors positive and negative for the Engrailed-1 (Enl) reporter gene were identified in mouse dorsal skin. ${ }^{12}$ Approximately $70 \%$ of dermal fibroblasts derived from the $E n I^{+}$population, and strikingly, these cells were also responsible for the deposition of dermal ECM during experimental wound healing and fibrosis. In contrast, based on neural crest-specific Wnt1 reporter gene expression, the ECM-producing cells in mouse oral mucosa derived from the neural crest and displayed a distinct gene expression profile and an attenuated fibrotic response as compared to mesoderm-derived $\mathrm{EnI}^{+}$skin cells. The profibrotic skin fibroblast population could be prospectively isolated from adult mouse dermis based on high expression of CD26. ${ }^{12}$ Thus, it is possible that the developmentally determined $\mathrm{CD} 26^{+}$fibroblast subpopulation in skin is involved in fibrosis and pathological scar formation. However, this has not been tested in experimental models relevant for human wound healing. Furthermore, it is not known whether the attenuated fibrosis response in oral mucosal wounds relates to the possible absence of the $\mathrm{CD} 26^{+}$profibrotic fibroblast population or whether it is an inherent property of oral mucosal cells. Therefore, we compared CD26 expression and localization in gingival and skin wounds over time using a red Duroc pig model. This model has been extensively used to study hypertrophic-like scar formation and closely mimics the human wound-healing response. , $^{8,46}$ In these pigs, wound healing in oral mucosal gingiva results in significantly reduced scar formation, as assessed by histological, molecular, and clinical parameters, as compared to skin wounds of similar size, which formed hypertrophic-like scars within 60 days of wounding. ${ }^{7}$ To further validate the findings in human tissues, we also studied expression of CD26 in human oral mucosal gingival and skin fibroblasts in vivo. Using threedimensional (3D) in vivo-like human gingival (GFBL) and skin fibroblast (SFBL) cultures established from different donors, we also characterized fibroblast populations based on their CD26 expression and assessed their key wound-healing and fibrosis-related phenotypic differences. We hypothesized that CD26 is highly expressed by SFBLs, and this is linked to their profibrotic phenotype, distinct from GFBLs.

\section{Materials and Methods}

\section{Animal Experiments}

Red Duroc pig tissue samples used in the study were collected as part of our previous study that assessed wound healing and scar formation in oral mucosal palatal gingiva and skin in these animals. ${ }^{7}$ Briefly, before experimental wounding, 12 juvenile, female, red Duroc pigs (Neufeld Farm, Acme, AB, Canada) were premedicated with ketamine and acepromazine, and general anesthesia was induced by $1 \%$ to $2 \%$ isofluorane by mask. Full-thickness excisional wounds $(15 \times 27 \mathrm{~mm})$ were generated in maxillary attached gingiva of the hard palate and dorsal skin on both sides of the midline of each pig. In total, one palatal and 10 skin wounds (minimum of $20 \mathrm{~mm}$ apart) were generated on each side of each pig. To generate wounds in the oral mucosa, full-thickness tissue near to the depth of the palatal bone was removed, leaving some soft tissue above the 
periosteum. In the skin, the epidermis, dermis, and subcutaneous fat were removed, exposing the underlying fascia. Pigs were divided into two experimental groups consisting of six pigs each. One group received wounds that were collected after 3 and 28 days of healing, whereas the other group received 14- and 60-day wounds. The tissue excised to generate the wounds was collected at the time of wounding to represent nonwounded tissue (day 0 samples). The oral mucosal wounds were left to heal untreated, whereas the skin wounds were sprayed with gentamycincontaining wound spray and bandaged. Wounding was timed to allow all of the animals to be sacrificed at the same time. To this end, tissue samples representing the wound and $3 \mathrm{~mm}$ of the surrounding tissue were collected at days 3 , 14,28 , and 60 after wounding and split in half at the midline of the wound. One half of each sample was processed for histological and immunohistochemical analysis and stored at $-80^{\circ} \mathrm{C}$ until used, ${ }^{7}$ whereas the other half was immediately snap frozen in liquid nitrogen and stored at $-80^{\circ} \mathrm{C}$ until total RNA isolation for gene expression analyses (see below). For the mRNA expression analyses described in this study, samples from six randomly selected pigs of the total of 12 pigs were used, yielding three parallel oral mucosal palatal gingival and skin samples from nonwounded tissue and wounds in three different pigs at each time point (days $0,3,14,28$, and 60). All samples were assessed separately in the analyses described below. For histochemical analysis of CD26 (see below), a minimum of six serial sections from four gingival and skin wounds in four parallel animals at each time point were used. All procedures were reviewed and approved by the Animal Care Committee of the Faculty of Medicine, University of Calgary (Calgary, AB, Canada; protocol number M03037.M08025, 2009).

\section{Human Tissue Samples and Fibroblasts}

Frozen tissue sections from normal human breast (from two 31-year-old female donors) and abdominal (from a 55-yearold male donor) skin of healthy subjects were obtained from Origene Technologies Inc. (Rockville, MD). Frozen gingival tissue sections were prepared from tissue biopsy specimens from healthy marginal and attached gingiva collected from four healthy human volunteers (from 19- and 40-year-old females and 35- and 53-year-old males) during routine crown lengthening procedures. A minimum of three parallel sections from each sample were used for analyses. Primary dermal fibroblasts (SFBLs) from clinically healthy human breast (six cell lines) and abdominal skin (three cell lines) from different donors were obtained from PromoCell (Heidelberg, Germany) and LifeLine Cell Technology (Frederick, MD), respectively (Table 1). Twelve gingival fibroblast lines (GFBLs) were isolated, as previously described, ${ }^{47}$ from clinically healthy gingiva from healthy human donors (Table 1). We have previously performed a detailed characterization of cell proliferation, morphology, and expression of 65 wound-healing-associated genes, and
Table 1 List and Origin of the Fibroblast Lines Used

\begin{tabular}{llll}
\hline Cell line & Tissue of origin & Sex & Age, years \\
\hline GFBL-DC & Attached gingiva & Male & 41 \\
GFBL-0L & Attached gingiva & Male & 30 \\
GFBL-HN & Attached gingiva & Female & 18 \\
GFBL-DW & Attached gingiva & Female & 30 \\
GFBL-IE & Attached gingiva & Male & 26 \\
GFBL-I7 & Attached gingiva & Male & 37 \\
GFBL-JNe & Attached gingiva & Female & 12 \\
GFBL-JNd & Attached gingiva & Female & 12 \\
GFBL-MBe & Attached gingiva & Male & 14 \\
GFBL-MBd & Attached gingiva & Male & 14 \\
GFBL-S0 & Attached gingiva & Female & 69 \\
GFBL-KS & Attached gingiva & Female & 28 \\
SFBL-2-C & White breast dermis & Female & 40 \\
SFBL-1-2 & White breast dermis & Female & 44 \\
SFBL-4-1 & White breast dermis & Female & 41 \\
SFBL-302 & White breast dermis & Female & 38 \\
SFBL-C12302 & White breast dermis & Female & 41 \\
SFBL-406 & White breast dermis & Female & 35 \\
SFBL-35 & White abdominal dermis & Female & 38 \\
SFBL-03 & White abdominal dermis & Female & 35 \\
SFBL-20 & White abdominal dermis & Female & 34 \\
\hline & & &
\end{tabular}

a set of proteins, by five and eight of these gingival and skin cell lines, respectively, in $3 \mathrm{D}$ cultures. ${ }^{26}$ Cells were routinely maintained in Dulbecco's modified Eagle's medium, supplemented with $10 \%$ fetal bovine serum and $1 \%$ antibiotic/antimycotic (Gibco Life Technologies, Inc., Grand Island, NY) at $37^{\circ} \mathrm{C}$ and $5 \% \mathrm{CO}_{2}$. Cells were seeded for experiments when at approximately $95 \%$ confluence. Experiments were performed at passages 3 to 10 . Gingival tissue donors provided a written informed consent. Privacy rights were observed, and procedures were reviewed and approved by the Office of Research Ethics of the University of British Columbia (Vancouver, BC, Canada).

\section{D Culture of Human Gingival and Skin Fibroblasts}

Fibroblasts were seeded at high density $\left(5 \times 10^{4}\right.$ cells $\left./ \mathrm{cm}^{2}\right)$ on culture plates in Dulbecco's modified Eagle's medium supplemented with $10 \%$ fetal bovine serum, $1 \%$ antibiotic/ antimycotic mixture, and $50 \mu \mathrm{g} / \mathrm{mL}$ of ascorbic acid. ${ }^{26,48}$ Cells were allowed to grow and generate an in vivo-like 3D culture for 7 days, with medium change three times per week, and processed for further analysis, as described below.

\section{Immunostaining of Cell Cultures and Tissue Sections}

For immunostaining, 3D cultures were generated on glass coverslips coated with $0.2 \%$ gelatin in phosphate-buffered saline (PBS), as described previously. ${ }^{26}$ Cultures were then fixed in $4 \%$ formaldehyde at room temperature for $20 \mathrm{mi}-$ nutes. Tissue sections were fixed with ice-cold acetone at room temperature for 5 minutes. Immunostainings were 
performed, as described previously, ${ }^{26}$ using appropriate species-specific Alexa-conjugated secondary antibodies (Alexa 488/594; Molecular Probes Inc., Thermo Fisher Scientific, Waltham, MA). For double immunostaining, incubation for each primary antibody was performed separately, as above, followed by incubation with appropriate secondary antibodies at the same time. Nuclear staining was performed using $300 \mathrm{nmol} / \mathrm{L}$ DAPI (Molecular Probes Inc.) in PBS for 5 minutes. Negative control staining was performed by omitting the primary antibody incubation step. Samples were mounted in Immu-Mount solution (Thermo Fisher Scientific). Standardized digital images were acquired using a Nikon Eclipse 80i microscope and NISElements version 4.20 software (Nikon Instruments Inc., Melville, NY). For quantification of immunostaining intensity of cell cultures generated on coverslips, standardized digital images were acquired from five nonoverlapping fields on each coverslip using a $10 \times$ objective. Immunostaining intensity and number of DAPI-stained nuclei as a measure of cell numbers per field were quantified by using ImageJ software version 1.51h (NIH, Bethesda, MD; http:// imagej.nih.gov/ij). The results are presented as staining intensity per cell.

\section{Histochemical Staining of CD26}

Because of lack of antibodies that recognize specifically pig CD26 in frozen sections, we performed histochemical staining of CD26 using a previously described method, with slight modifications. ${ }^{49}$ To validate the method, we also performed immunostaining of human cell cultures and tissue sections using both the anti-human CD26 antibody, as above, and the histochemical method. The histochemical method detects CD26/DPP4-specific enzymatic activity using Gly-Pro-4-methoxy-ß3-naphthylamide substrate (G9137; Sigma-Aldrich, St. Louis, MO) and Fast Blue B stain (Sigma-Aldrich). Briefly, 3D fibroblast cultures and frozen tissue sections ( $5 \mu \mathrm{m}$ thick) were fixed with ice-cold acetone at room temperature for 5 minutes, air dried, and washed with PBS. To prepare the dye stock solution, Fast Blue B was dissolved in double-distilled water $(3 \% \mathrm{w} / \mathrm{v})$ by shortly heating the solution to $95^{\circ} \mathrm{C}$. The substrate stock solution was prepared to contain 2\% (w/v) Gly-Pro-4methoxy- $\beta$-naphthylamide in $\mathrm{N}, \mathrm{N}$-dimethylformamide (number 227056; Sigma-Aldrich). The final staining solution was mixed immediately before use and contained $2.5 \%$ (v/v) substrate stock solution in PBS and $0.3 \%$ (v/v) Fast Blue B. Cultured cells and tissue sections were covered with the staining solution and incubated in a humid chamber at $37^{\circ} \mathrm{C}$ for 2 and 20 hours, respectively. The reaction was stopped by rinsing with PBS, and the sections were mounted in $50 \%$ glycerol and a coverglass sealed with nail polish. Control staining was performed omitting the CD26 substrate from the reaction solution. The samples were observed using a light microscope, and standardized digital images were acquired, as above.

\section{Fluorescence-Activated Cell Sorting}

Fluorescence-activated cell sorting analysis for cell surface CD26 expression was performed, as described previously. ${ }^{50}$ Briefly, fibroblasts were grown in 3D cultures for 7 days, as described above, and the cultures were then trypsinized. Single-cell suspensions were immunostained with $10 \mu \mathrm{g} / \mathrm{mL}$ polyclonal anti-CD26 antibody (Table 2). Anti-goat Alexa Fluor $488 \mathrm{IgG}$ (Molecular Probes Inc.) was used as the secondary antibody. Control immunostaining was performed using the secondary antibody only. The immunolabeled cells were analyzed using a BD LSRII Flow Cytometer (BD Biosciences, San Jose, CA).

\section{Generation of Decellularized Fibroblast-Derived 3D ECMs}

Decellularized 3D ECMs were prepared, as previously described. ${ }^{48}$ Briefly, fibroblasts were grown for 7 days, as

Table 2 List of Antibodies Used in the Study

\begin{tabular}{lllll}
\hline & & & & \\
\cline { 3 - 4 } Antibody & Manufacturer & Source & Immunostaining/FACS & Western blotting \\
\hline Anti-CD26 (AF1180) & R\&D Systems Inc. (Minneapolis, MN) & Goat & $5 \mu \mathrm{g} / \mathrm{mL} / 10 \mu \mathrm{g} / \mathrm{mL}$ & $200 \mu \mathrm{g} / \mathrm{mL}$ \\
Anti-CD31 (clone WM-59; no. 555444) & BD Biosciences (San Diego, CA) & Mouse & $1: 30$ & \\
Anti-CD68 (clone EBM11; no. M0718) & Dako (Glostrup, Denmark) & Mouse & $1: 50$ \\
Mab 27E10 & Abcam Inc. (Cambridge, MA) & Mouse & $1: 10$ \\
Mab 25F9 & Abcam Inc. & Mouse & $1: 200$ & \\
Anti-myeloperoxidase (ab15484) & Abcam Inc. & Rabbit & $1: 20$ & \\
Anti-vimentin (VIM384) & Progen Biotechnik (Heidelberg, Germany) & Mouse & $1: 200$ & \\
Anti-laminin-111 (L9393) & Sigma-Aldrich (St. Louis, M0) & Rabbit & $1: 50$ & \\
Anti- $\alpha$-smooth muscle actin (1A4) & Sigma-Aldrich & Mouse & $1: 100$ & \\
Anti-human SMAD3 (ab28379) & Abcam Inc. & Rabbit & & $1: 2000$ \\
Anti-human phospho-SMAD3 (ab52903) & Abcam Inc. & Rabbit & & $1: 2000$ \\
Anti-human $\beta$-actin (ab8227) & Abcam Inc. & Rabbit & & $1: 5000$ \\
\hline
\end{tabular}

FACS, fluorescence-activated cell sorting. 
above, to generate 3D cultures, washed once with PBS, and then incubated with a cell extraction buffer $(0.5 \%$ Triton $\mathrm{X}-100$ and $20 \mathrm{mmol} / \mathrm{L} \mathrm{NH}_{4} \mathrm{OH}$ in PBS; pH 8.0) at $37^{\circ} \mathrm{C}$ for 5 to 10 minutes. An equal volume of PBS was then added to dilute the extraction buffer twofold, and the cultures were incubated at $4{ }^{\circ} \mathrm{C}$ overnight. The 3D ECM was then washed with PBS and treated with $10 \mathrm{U} / \mathrm{mL}$ of DNase (Roche Diagnostics, Indianapolis, IN) at $37^{\circ} \mathrm{C}$ for 30 minutes. After three gentle washes with PBS, the cell-free 3D ECMs were stored at $4^{\circ} \mathrm{C}$ until used. To confirm the removal of cells, a set of decellularized 3D ECMs was treated with DAPI nuclear stain, as above, and the absence of nuclei was confirmed by fluorescence microscopy (data not shown).

Fibroblast Reseeding on Decellularized Homotypic and Heterotypic Fibroblast-Derived 3D ECM and Collagen Substrates

For experiments assessing interaction of GFBLs and SFBLs with decellularized homotypic and heterotypic 3D ECMs, fibroblasts $\left(4 \times 10^{4}\right.$ cells $\left./ \mathrm{cm}^{2}\right)$ were seeded on the decellularized 3D ECMs prepared, as above, in serum-free Dulbecco's modified Eagle's medium. After 24 hours of cell culture, cell extracts were processed for analysis by quantitative RT-PCR (RT-qPCR) or Western blotting, as described below. To generate control substrates, tissue culture plates were coated with $100 \mu \mathrm{g} / \mathrm{mL}$ of collagen type I (PureCol; Advanced BioMatrix, Poway, CA) in $10 \mathrm{mmol} /$ $\mathrm{L} \mathrm{HCl}$ at room temperature for 1 hour. Before cell seeding, non-specific binding sites were blocked with $1 \%$ bovine serum albumin in PBS at room temperature for 30 minutes. Experiments were performed using four parallel GFBL and SFBL lines from different donors and decellularized 3D ECMs from these cell lines, in different pairwise combinations of cells and decellularized 3D ECMs.

\section{Blocking of CD26 Activity and Autogenous TGF- $\beta$ Signaling, and TGF- $\beta 1$ and TGF- $\beta 3$ Treatment}

Fibroblasts were cultured for 7 days to generate 3D cultures, as described above. To block CD26 function, cultures were treated for 24 hours with increasing concentrations of diprotin A (0 to $10 \mathrm{mmol} / \mathrm{L}$; Ile-Pro-Ile; Enzo Life Sciences, Burlington, ON, Canada) or sitagliptin (0 to $100 \mu \mathrm{mol} / \mathrm{L}$; catalog number 1757; BioVision, Milpitas, CA), specific competitive inhibitors of the catalytic activity of CD26 that have antifibrotic effects in vivo. ${ }^{12,51,52}$ To confirm functionality of the inhibitors, cells were cultured in the presence or absence of the inhibitor for 24 hours, followed by histochemical CD26/DPP4 staining, as above, in the presence or absence of the inhibitor. To block autogenous transforming growth factor- $\beta$ (TGF- $\beta$ ) signaling, 3D cultures were serum starved for 24 hours and then treated in serum-free medium with $20 \mu \mathrm{mol} / \mathrm{L}$ of SB-431542 (Selleckchem, Houston, TX), an inhibitor of TGF- $\beta$ receptor kinase activity, for 24 hours. Control samples were treated with corresponding concentrations of the drug diluent (dimethyl sulfoxide). In a set of experiments, serum-starved 3D cultures were treated with increasing concentrations ( 0 to $50 \mathrm{ng} / \mathrm{mL}$ ) of recombinant TGF- $\beta 1$ (catalog number GF111; EMD Millipore Corp., Temecula, CA) or TGF- $\beta 3$ (catalog number 4344-5; BioVision) for 24 hours. Total RNA and protein were isolated from the cell lysates for RT-qPCR and Western blotting, respectively, as described below.

\section{Western Blotting}

The abundance of CD26 and activation of intracellular signaling pathways were analyzed in GFBL and SFBL 3D cultures 7 days after seeding by Western blotting. To prepare cell lysates, fibroblasts were washed with ice-cold PBS and incubated in $20 \mathrm{mmol} / \mathrm{L} 3$-(N-morpholino)propanesulfonic acid (pH 7.2) containing $2 \mathrm{mmol} / \mathrm{L}$ EGTA, $5 \mathrm{mmol} / \mathrm{L}$ EDTA, $1 \%$ Triton X-100, and Complete Protease Inhibitor Cocktail (Roche Diagnostics). Lysates were then collected using a rubber policeman, sonicated on ice, and centrifuged at 5000 $\times g$ for 1 minute. Total protein concentration in the cell extracts was determined using DC Protein Assay (Bio-Rad, Mississauga, ON, Canada). SDS sample buffer containing 5\% 2-mercaptoethanol was added to the samples, and equal amounts of protein were loaded into $7.5 \%$ to $12 \%$ SDS-polyacrylamide gels, separated by electrophoresis, and transferred onto a Protran nitrocellulose membrane (Amersham Biosciences, Little Chalfont, Buckinghamshire, UK), as described previously. ${ }^{26}$ Immunoblotting was performed, as described previously, using a set of primary antibodies (Table 2) and appropriate species-specific IRdye-conjugated secondary antibodies (1:10,000; LI-COR Biosciences, Lincoln, NE). ${ }^{26}$ The blots were detected using the Odyssey Infrared Imaging system (LI-COR Biosciences). The results were quantified using the Odyssey application software version 3.0 (LI-COR Biosciences).

\section{RNA Isolation}

To extract RNA from frozen pig tissue, samples were first cut into small pieces with a razor blade on dry ice and then pulverized by grinding with mortar and pestle over liquid nitrogen. The tissue powder was stored at $-80^{\circ} \mathrm{C}$ until use. For RNA extraction, up to $50 \mathrm{mg}$ of each powdered tissue sample was weighed into a prechilled $2-\mathrm{mL}$ microcentrifuge tube, and $500 \mu \mathrm{L}$ of Trizol Reagent (Ambion, Life Technologies, Inc., Burlington, ON, Canada) was added to the samples, which were then immediately homogenized with a PowerGen 1000 rotor-stator homogenizer (Fisher Scientific, Ottawa, ON, Canada) at 35,000 rpm using a hard-tissue Omni-tip (Omni International, Marietta, GA). The samples were then centrifuged at $12,000 \times g$ at $4{ }^{\circ} \mathrm{C}$ for 10 minutes to remove tissue debris. Chloroform $(100 \mu \mathrm{L})$ was added to the cleared supernatants, and the tubes were shaken vigorously by hand for 15 seconds, followed by incubation at room temperature for 2 to 3 minutes. The samples were then centrifuged at 
$12,000 \times g$ at $4{ }^{\circ} \mathrm{C}$ for 15 minutes, and the aqueous phase was transferred to a new tube. Ethanol $(70 \% ; 275 \mu \mathrm{L})$ was added to the samples, and total RNA was extracted using a NucleoSpin RNA kit (Macherey-Nagel, Bethlehem, PA), according to the manufacturer's instructions. RNA concentration and quality were evaluated spectrophotometrically and with the Agilent 2100 Bioanalyzer (Agilent Technologies, Santa Clara, CA), respectively.

To isolate RNA from human fibroblast cultures, it was extracted using a NucleoSpin RNA II kit and treated with rDNase, according to the manufacturer's protocol (MachereyNagel). Total RNA concentration and purity were measured by spectrophotometry (GeneQuant Pro; Amersham Biosciences), and RNA integrity was assessed by electrophoresis using an agarose gel containing formaldehyde, followed by staining of RNA with $0.5 \mu \mathrm{g} / \mathrm{mL}$ of ethidium bromide in 0.1 $\mathrm{mol} / \mathrm{L}$ ammonium acetate for 30 minutes. Samples with an OD $260 / 280$ ratio of 1.8 to 2.0 and an $18 \mathrm{~S} / 21 \mathrm{~S}$ rRNA ratio of approximately 2.1 were used for the study.

\section{RT-qPCR}

RT-qPCR analysis was performed according to Minimum Information for Publication of Quantitative Real-Time PCR Experiments guidelines. ${ }^{53}$ Briefly, cDNA was synthesized using an iScript Select cDNA Synthesis Kit (Bio-Rad), according to the manufacturer's instructions. To this end, $1 \mu \mathrm{g}$ of total RNA was reverse transcribed by adding $4 \mu \mathrm{L}$ of $5 \times$ reaction buffer, $2 \mu \mathrm{L}$ of random primers, $1 \mu \mathrm{L}$ reverse transcriptase, and nuclease-free water to a final volume of $20 \mu \mathrm{L}$. The cDNA was synthesized using a Mastercycler gradient 5331 Reverse-Transcriptase PCR Instrument (Eppendorf AG, Hamburg, Germany) using the following program: one cycle at $25^{\circ} \mathrm{C}$ for 5 minutes, one cycle at $42^{\circ} \mathrm{C}$ for 30 minutes, and $85^{\circ} \mathrm{C}$ for 5 minutes. Primers used for RT-qPCR have been described previously. ${ }^{26}$ In addition, we used the following primers for human CD26 (DPP4; NM_001935): forward, 5'-AGTCGCAAAACTTACACTCTAACTG-3'; and reverse, 5'-GAGCTGTTTCCATATTCAGCATTG- $3^{\prime}$. We used the following primers for pig CD26 (NM_214257): forward, 5'-AGTCGCAGAACCTACACG-3'; and reverse, 5'-GAGCTGTTTCCATATTCAGCATTG- $3^{\prime}$. All primers were designed on the boundaries of exons when possible and analyzed by BLASTn software version 2.3.0 (National Center for Biotechnology Information, US National Library of Medicine, Bethesda, MD; http://blast.ncbi.nlm.nih.gov/Blast.cgi) for specificity. The primers were designed to yield a 75- to 150-bp long target sequence with a GC content between $40 \%$ and $70 \%$. Efficiency of the target amplification, including annealing temperature, primer, and sample concentration, was optimized to up to $95 \%$ for each primer set using a 10-fold dilution series of cDNA while standard curves were generated. For the reaction, cDNA from each sample was diluted to a concentration such that the $\mathrm{Cq}$ values were well within the range of their standard curves, and the diluted cDNA was mixed with $2 \mathrm{X}$ iQ SYBR Green I Supermix (Bio-Rad) and 5 pmol/L of primers. PCR amplification was performed on the CFX96 System (Bio-Rad) using the following program: one cycle at $95^{\circ} \mathrm{C}$ for $3 \mathrm{mi}-$ nutes, 35 cycles at $95^{\circ} \mathrm{C}$ for 10 seconds, $60^{\circ} \mathrm{C}$ for $20 \mathrm{sec}$ onds, and reaction completion with reading plate and a melt curve analysis from $65^{\circ} \mathrm{C}$ to $95^{\circ} \mathrm{C}, 5$ seconds for each $0.5^{\circ} \mathrm{C}$.

Amplification reactions were conducted for human target genes with ubiquitin $\mathrm{C}(U B C)$, TATA box-binding protein $(T B P), \beta$-2-macroglobulin $(B 2 M)$, glyceraldehyde-3phosphate dehydrogenase $(G A P D H)$, hypoxanthine phosphoribosyltransferase I (Hprtl), 18s rRNA, and asparagine-linked glycosylation $9(A L G 9)$ as reference genes. ${ }^{26}$ For RT-qPCR of pig mRNA, the following reference genes were also used: UBC (XM_001925271), 5'-TGCCGCTATACAATGCAG-3' (forward) and 5'-GACATTCTCAA-

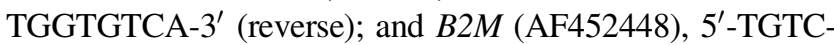
TTTCAGCAAGGACTGGTCTTTC- $3^{\prime}$ (forward) and $5^{\prime}$ TGCTTCACGCGGCAGCTATAC-3' (reverse). The reference genes have been previously validated for stability in various pig tissues. ${ }^{54}$ For a given experiment, at least two bestqualified reference genes were chosen using the integrative RefFinder tool. ${ }^{55}$ Non-reverse-transcribed RNA samples were used as a negative control. The PCRs were performed in triplicate for each tissue sample and cell line. The data were analyzed and are presented based on the comparative $\mathrm{Cq}$ method (CFX Manager Software version 2.1; Bio-Rad).

\section{Transfection with siRNA}

SFBLs $\left(3.5 \times 10^{5}\right)$ were seeded into 6 -well plates in $3 \mathrm{~mL}$ of growth medium, cultured for 24 hours, and then transfected with siRNA using Lipofectamine RNAiMax reagent (Invitrogen Inc., Burlington, ON, Canada). To this end, 7.2 $\mu \mathrm{L}$ of Lipofectamine RNAiMax and $50 \mathrm{pmol} / \mathrm{L}$ of siRNA were individually diluted into $400 \mu \mathrm{L}$ of Opti-MEM (Invitrogen Inc.) at room temperature for 5 minutes. The solutions were then combined and incubated at room temperature for 20 minutes. Opti-MEM $(800 \mu \mathrm{L})$ was then added to the mixture for the final siRNA concentration of $30 \mathrm{nmol} / \mathrm{L}$. A set of parallel cultures was treated with a combination of CD26siRNA1 and CD26-siRNA2 (15 nmol/L each). Cells were incubated with $1.6 \mathrm{~mL}$ of the siRNA mixture for 5 hours before adding $1.4 \mathrm{~mL}$ of growth medium to each well. After overnight culture, the medium was replaced with the regular growth medium and cells were cultured until mRNA and protein isolation after 2 and 6 days. The siRNA sequences (Sigma-Aldrich) were as follows: Control-siRNA, 5'-ACUUCGACACAUCGACUGC [dT][dT]-3'; CD26SiRNA1， 5'-UUAAGUAAUCAGUUAGAGUGU-3'; and CD26-siRNA2, 5'-AUCUUAAGGAGUAUAACUUCA-3'.

\section{Cell Proliferation Assay}

SFBLs $\left(5 \times 10^{3}\right.$ cells/well; SFBL-1-2, SFBL-4-1, SFBL-03, and SFBL-20) were seeded into 96-well-plate wells in 
quadruplicate for each cell line, treatment (control, no treatment; Cont-siRNA; CD26-siRNA1; CD26-siRNA2; and sitagliptin, 30 or $100 \mu \mathrm{mol} / \mathrm{L})$, and time point $(1,2,4$, and 6 days), and cultured in their normal growth medium. At the indicated time points, the number of viable cells in each well was determined using a CellTiter 96 NonRadioactive Cell Proliferation Assay kit (Promega Inc., Madison, WI), according to the manufacturer's instructions. The results were quantified using a Microplate reader model 3550 (Bio-Rad) at a wavelength of $595 \mathrm{~nm}$.

\section{Statistical Analysis}

All cell culture data are expressed as means \pm SEM of up to 12 parallel GFBL and up to 9 SFBL lines and/or from a minimum of three repeated experiments. Statistical analysis was performed using $t$-test, and multiple comparisons were performed by analysis of variance with post hoc Bonferroni test $P<0.05$ was considered statistically significant. Values obtained from the RT-qPCR by the comparative $\mathrm{Cq}$ method were $\log 2$ transformed for statistical testing. ${ }^{56}$

\section{Results}

Persistent Accumulation of CD26-Positive Cells in Hypertrophic Scars in Skin Compared to Scarless Healing of Oral Mucosal Gingiva in the Red Duroc Pigs

To assess the role of CD26 in wound healing that results in hypertrophic-like scar formation, we used tissue samples obtained from our previously validated red Duroc pig model. ${ }^{7}$ RT-qPCR analysis using RNA isolated from these pigs showed significantly higher expression of CD26 (approximately sixfold) and type I collagen (a hallmark of scar formation and fibrosis; approximately threefold) in nonwounded (day 0) skin as compared to gingiva (Figure 1, A and B). We then analyzed their mRNA levels in samples obtained at days 3 (early inflammatory stage of wound healing; reepithelialization and granulation tissue formation have started), 14 (reepithelialization and granulation tissue formation are underway), 28 (wounds have reepithelialized and remodeling of wound connective tissue is underway), and 60 (gingival wounds show regeneration of normal tissue form while skin wounds have formed hypertrophic-like scars) after wounding. ${ }^{7}$ In nonwounded skin and in skin wounds 28 and 60 days after wounding, expression of CD26 (approximately fourfold to sixfold) and type I collagen (approximately twofold to threefold) was significantly higher than in gingiva (Figure 1, A and B). In skin wounds, there was no significant change in expression of total CD26 mRNA over the course of wound healing as compared to nonwounded skin. In contrast, gingival wounds showed a significant but transient up-regulation of CD26 expression (approximately fourfold) as compared to nonwounded tissue at days 3 and 14 after wounding (Figure 1A). This was followed by a robust down-regulation of CD26 expression, returning to the level of nonwounded tissue by day 60 (Figure 1A). Thus, nonwounded skin and developing hypertrophic-like skin scars display significantly higher expression of CD26 and type I collagen relative to gingiva, suggesting that CD26-expressing cells in nonwounded skin are already primed for a profibrotic response before wounding. In contrast, gingival cells expressing CD26 appear temporarily at the wound site, but they disappear during the remodeling stage of healing.

To analyze CD26 localization in the same animals, we used histochemical staining that detects enzymatic activity specific for CD26. ${ }^{49}$ Neither gingiva nor skin epithelium showed specific CD26 staining (Figure 1, C and E). In nonwounded gingiva, CD26 localized most strongly to blood vessels, whereas only rare connective tissue cells showed weak staining (Figure 1, C and D). During early gingival wound healing at days 3 and 14, many inflammatory cells within the fibrin clot showed CD26 staining (data not shown). At day 3, CD26 staining increased also in the connective tissue and localized to the forming blood vessels and sparse cells closely associated with them at the wound edge (Figure 1, J and K). At day 14, CD26 showed strong staining in the newly formed blood vessels and weaker staining in fibroblastic cells within the granulation tissue (Figure 1, P and Q). Localization of CD26 to blood vessels at days 3 and 14 was confirmed by immunofluorescence staining of parallel sections with an antibody against laminin-111, a marker for vascular basement membranes (Supplemental Figure S1, A, B, E, and F). At day 28, blood vessels and connective tissue cells within the contracting wound (Figure 1, V and W) showed moderate CD26 staining. At day 60, CD26 staining had decreased to the level of nonwounded gingiva and localized mostly to the blood vessels, similar to the normal tissue (Figure 1, BB and CC).

Like gingiva, nonwounded skin contained blood vessels that were positive for CD26. In contrast to gingiva, however, many connective tissue cells that displayed typical morphology of fibroblasts in subepithelial (papillary) dermis showed moderate CD26 staining, whereas in the deeper tissue the staining was present in fewer cells (Figure 1, E and $\mathrm{F}$, respectively). In addition, some connective tissue cells around hair follicles (Figure 1G) and in the subcutaneous adipose tissue (Figure $1 \mathrm{H}$ ) were positive. During the early stages of skin wound healing, like in gingiva, inflammatory cells within the fibrin clot stained positively for CD26 (data not shown). Over the course of skin wound healing, there was a marked increase in staining intensity and number of CD26-positive fibroblast-like connective tissue cells around the wound margins. First, many cells within the connective tissue close to the wound edge, which appeared to migrate toward the wound, showed strong CD26 staining from day 3 to 14 after wounding (Figure 1, $\mathrm{L}-\mathrm{N}, \mathrm{R}$, and S). Second, at days 14 and 28, there was a strong increase in CD26-positive connective tissue cells associated with hair follicles close to the wound (Figure 1, T 
A

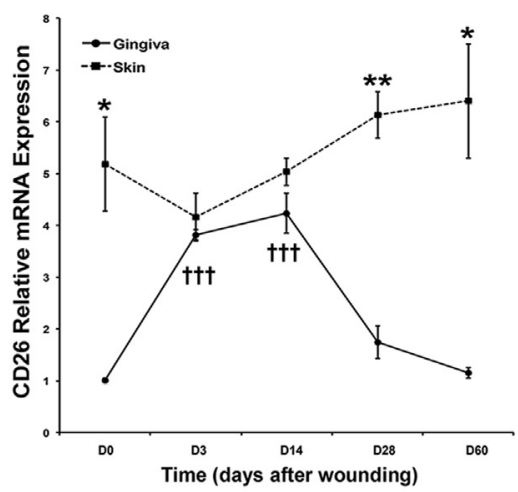

B

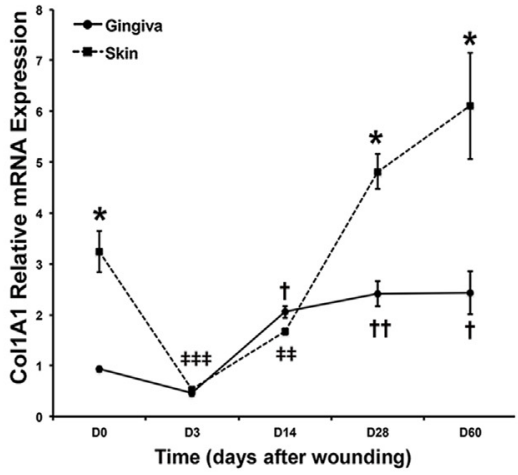

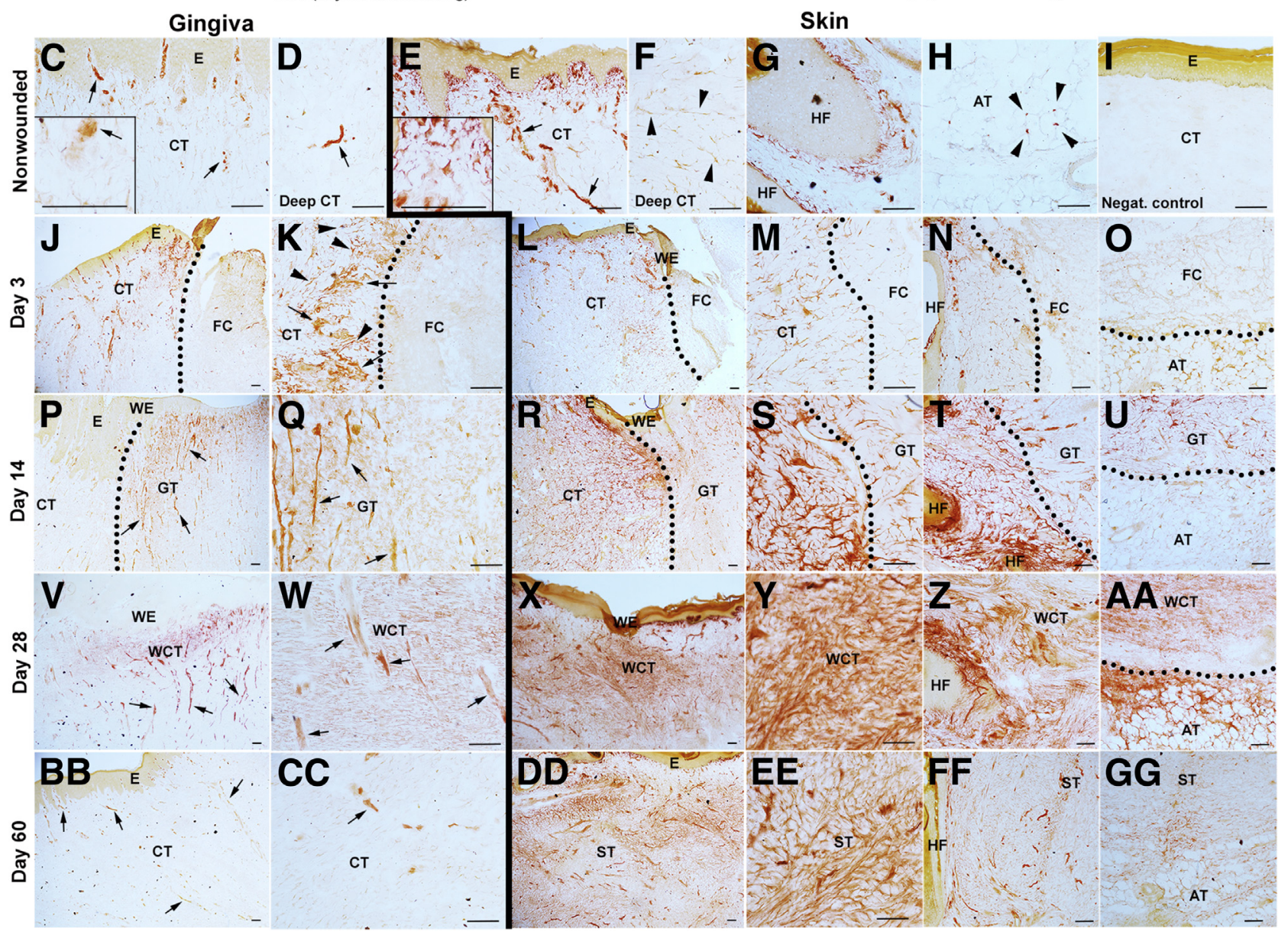

Figure 1 Increased abundance of CD26 in red Duroc pig skin as compared to gingiva associates with elevated expression of type I collagen and scar formation. A and B: RT-qPCR of CD26 (A) and type I collagen (Col1A1) (B) in red Duroc pig nonwounded tissue (D0) and in gingival and skin wounds at days 3 (D3), 14 (D14), 28 (D28), and 60 (D60) after wounding. Results show relative mRNA expression from three parallel wounds from three pigs in each tissue and time point. Statistical comparison between gingival and skin wounds at each time point was performed using $t$-test and analysis of variance. $\mathbf{C}-\mathbf{G G}$ : Representative images of histochemical staining of CD26 in red Duroc pig nonwounded tissues and wounds. Dotted lines indicate wound margin. Arrows show blood vessels positively stained for CD26; arrowheads, CD26-positive connective tissue cells in nonwounded deep dermal connective tissue (F) and adipose tissue $(\mathbf{H})$; insets in $\mathbf{C}$ and $\mathbf{E}$, higher-magnification images from connective tissue. Data are expressed as means \pm SEM $(\mathbf{A}$ and $\mathbf{B})$. ${ }^{*} P<0.05$, ${ }^{* *} P<0.01$ skin versus gingiva; ${ }^{\dagger} P<0.05,{ }^{\dagger \dagger} P<0.01$, and ${ }^{\dagger \dagger} P<0.001$ wound versus nonwounded tissue in gingiva; ${ }^{\ddagger \ddagger} P<0.01,{ }^{\ddagger \ddagger \ddagger} P<0.001$ wound versus nonwounded tissue in skin. Scale bars $=100 \mu \mathrm{m}(\mathbf{C}-\mathbf{G G})$. AT, adipose tissue; $\mathrm{CT}$, connective tissue; E, epithelium; FC, fibrin clot; GT, granulation tissue; HF, hair follicle; ST, scar tissue; WCT, wound connective tissue; WE, wound epithelium.

and Z, respectively). Third, as compared to days 3 and 14 after wounding (Figure 1, $\mathrm{O}$ and $\mathrm{U}$, respectively), there was also a strong increase in CD26-stained cells in the adipose tissue beneath the wound at day 28 (Figure 1AA). CD26- positive cells around hair follicles and within the adipose tissue appeared also to migrate toward the wound. Consequently, at day 28 after wounding, the developing scar tissue contained abundantly fibroblast-like cells that showed 
strong staining of CD26 (Figure 1, X and Y). As compared to nonwounded skin, the scar that had formed by day 60 contained markedly increased numbers of connective tissue cells that showed strong staining for CD26 (Figure 1, DD and EE), whereas CD26 staining around hair follicles (Figure 1FF) and adipose tissue (Figure 1GG) next to the scar was subsiding. Negative control stainings showed no staining in the connective tissue (Figure 1I).

Myofibroblasts are considered key drivers of ECM accumulation in various forms of organ fibrosis. ${ }^{57}$ To study the association of CD26 with myofibroblasts, we used CD26 histochemical and $\alpha$-smooth muscle actin ( $\alpha$-SMA; a marker of myofibroblasts) immunofluorescence staining in parallel wound sections. As compared to unwounded gingival (Supplemental Figure S3, A-C) and skin (Supplemental Figure S2, A-C) tissues, in both gingival (Supplemental Figure S3, G-O) and skin (Supplemental Figure S2, D-U) wounds, first myofibroblasts appeared by day 14 and their numbers peaked at day 28 after wounding, coinciding with wound contraction. At day 60 , myofibroblast abundance was more strongly reduced in skin wounds than in gingival wounds (Supplemental Figures S2, $\mathrm{V}-\mathrm{X}$, and $\mathrm{S} 3, \mathrm{P}-\mathrm{U})^{7}$ In some locations within both gingival (day 28) (Supplemental Figure S3, J-L) and skin wounds (days 14 and 28) (Supplemental Figure S2, D-F and $\mathrm{M}-\mathrm{R}$, respectively), CD26 staining localized to areas rich in myofibroblasts. However, in other gingival (days 14 and 28) (Supplemental Figure S3, D-F and $\mathrm{M}-\mathrm{O}$, respectively) and skin (day 28) (Supplemental Figure S2, $\mathrm{J}-\mathrm{L}$ ) wound locations, myofibroblasts did not show any CD26 staining. In wound areas close to hair follicles (Supplemental Figure S2, G-I) and adipose tissue (Supplemental Figure S2, S-U), cells were strongly positive for CD26, but did not show immunoreactivity for $\alpha$-SMA. At day 60, myofibroblasts present in gingival wounds did not stain for CD26 (Supplemental Figure S3, $\mathrm{S}-\mathrm{U})$. In contrast, scars formed in skin contained areas that were devoid of myofibroblasts but showed persistence of connective tissue cells, with strong staining for CD26 (Supplemental Figure S2, V-X). Thus, CD26 staining only partially overlapped with myofibroblast markers in both gingival and skin wounds, and CD26-positive cells, but not myofibroblasts, accumulated in hypertrophic-like scars formed in skin.

\section{Human Skin Contains Abundant CD26-Positive Fibroblasts Compared to Gingiva}

Having established that nonwounded skin and hypertrophiclike scars formed in the skin of red Duroc pigs contain more CD26-expressing cells than gingiva in red Duroc pigs, we wanted to study the presence of these cells in human skin and gingiva (Figure 2 and Supplemental Figure S1, C, D, G, and $\mathrm{H})$. In these samples, assessment of CD26 localization by immunochemical and histochemical staining gave results similar to what was found for respective tissues in the pigs
(Figure 2, A-H). Like in the pig samples, CD26 was not detected in human gingival or skin epithelium (Figure 2, $\mathrm{A}-\mathrm{H}$ ), and skin connective tissue contained markedly more cells that were strongly stained for CD26 than gingiva (Figure 2, A-H). In skin, the CD26-positive cells were most abundantly concentrated in the subepithelial (papillary) dermis, but positive cells were also spread throughout the deeper dermis. To identify cells expressing CD26, we performed double immunostainings with antibodies against CD26 and different cell markers. Human gingival connective tissue showed some cells that were positive for CD26, but they were negative for vimentin (a fibroblast marker), which suggests that CD26-positive cells were not fibroblasts (Figure 2, I-M). Further analysis showed that CD26 staining found in gingiva derived from endothelial cells (CD31 positive), neutrophil granulocytes (myeloperoxidase positive), and M1 (27E10 positive) and M2 (25F9 positive) macrophages, routinely present also in clinically healthy gingiva (Supplemental Figure S4). In contrast, in skin, the CD26-positive cells were also positive for vimentin (Figure 2, N-R). Double immunostaining performed with another fibroblast marker, type I procollagen, and CD26 confirmed these findings (Supplemental Figure S1, I-P). Thus, human gingiva contains few fibroblasts that show immunoreactivity for CD26, whereas CD26-positive fibroblasts are abundantly present in human skin in vivo.

\section{Human SFBL Cultures Show Significantly Elevated CD26 Abundance Compared to GFBLs}

Our findings from above suggested that in both red Duroc pigs and humans, CD26 expression defines distinct fibroblast populations in gingiva and skin in vivo, which may determine whether wound healing results in tissue regeneration (gingiva) or excessive scar formation (skin). To explore this possibility further, we compared fibroblast populations isolated from healthy human gingiva (GFBLs) from 12 individuals with SFBLs from abdominal and breast skin from nine individuals. Like in red Duroc pigs, human gingival wounds heal with little scar formation, $8,10,11$ whereas human breast and abdominal skin is prone to scar formation. ${ }^{58,59}$ For the experiments, we used our previously characterized $3 \mathrm{D}$ cell culture model ${ }^{26}$ that mimics the in vivo tissue niche better than standard two-dimensional cultures. ${ }^{60,61}$ In this model, cells become embedded in their own ECM and are stimulated by serum to proliferate and express a transcriptome that mimics wound healing. ${ }^{48,62}$ Findings showed that compared to GFBLs, SFBL cultures expressed significantly higher levels of CD26, as assessed by immunostaining (Figure 3, A-D), histochemical staining (Supplemental Figure S1, Q-V), fluorescence-activated cell sorting (Figure 3E), Western blotting (Figure 3, F and G), and RT-qPCR (Figure 3H and Supplemental Figure S5A). The high CD26 abundance in SFBL cultures associated with significantly elevated expression of type I collagen compared to GFBLs (Figure 3, I and K). Expression of 

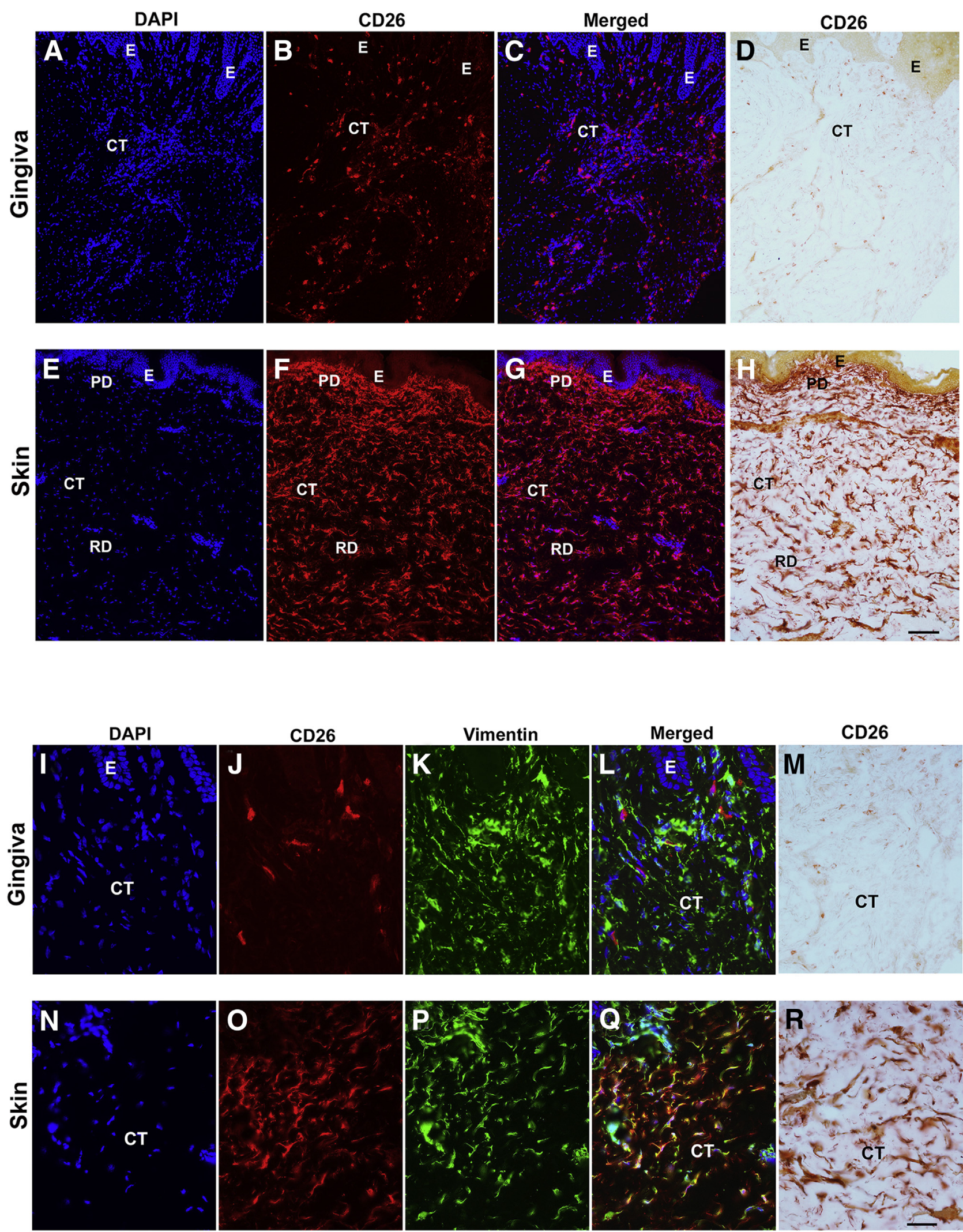

Figure 2 CD26-positive fibroblasts are abundantly present in human skin but absent from gingiva. A-H: Representative images of immunostaining of CD26 in human gingiva $(\mathbf{A}-\mathbf{C})$ and skin $(\mathbf{E}-\mathbf{G})$. Parallel gingival $(\mathbf{D})$ and skin $(\mathbf{H})$ tissue sections stained with histochemical CD26 stain, respectively. Nuclei were stained with DAPI (A-C and $\mathbf{E}-\mathbf{G})$. I-R: Representative images of double immunostaining of human gingival $(\mathbf{I}-\mathbf{L})$ and skin $(\mathbf{N}-\mathbf{Q})$ sections with antibodies against $\mathbf{C D} 26$ (red) and vimentin (green). Parallel gingival (M) and skin (R) tissue sections stained with histochemical CD26 stain, respectively. Nuclei were stained with DAPI (I, L, N, and Q). Scale bars: $200 \mu \mathrm{m}(\mathbf{A}-\mathbf{H}) ; 50 \mu \mathrm{m}(\mathbf{I}-\mathbf{R})$. CT, connective tissue; E, epithelium; PD, papillary dermis; RD, reticular dermis. 
A

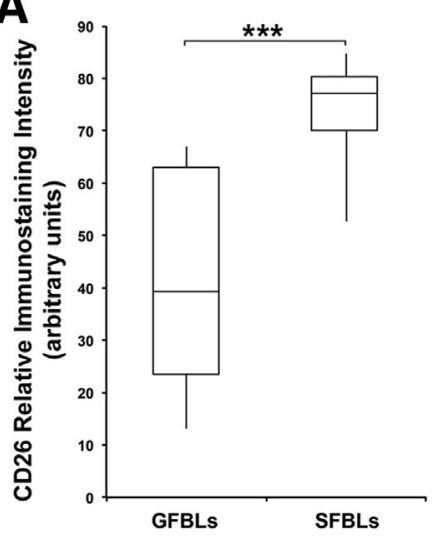

$\mathbf{F}$

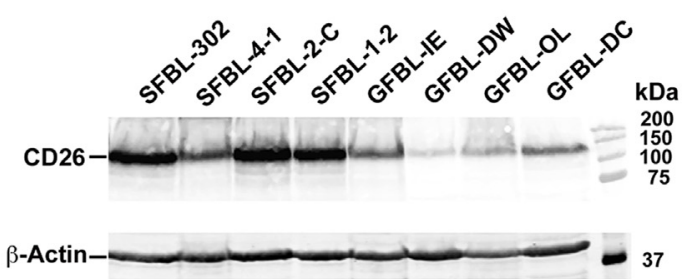

H

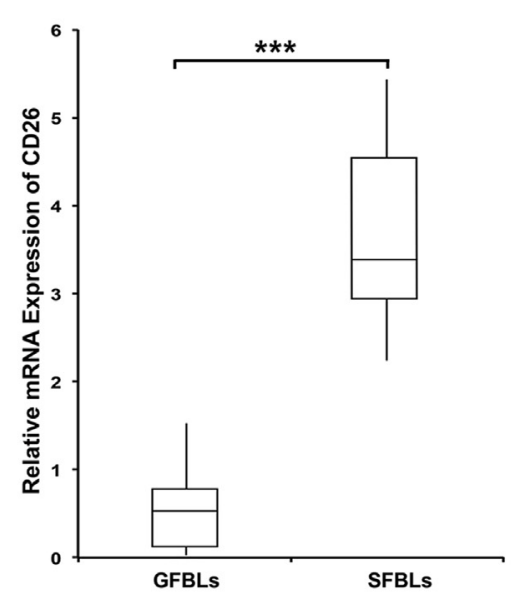

J

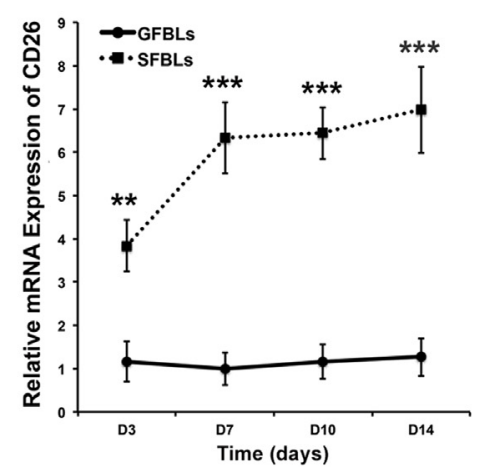

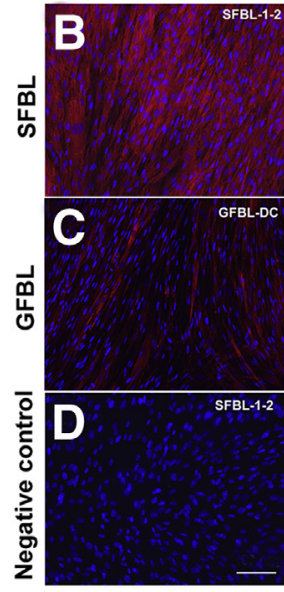

$E$

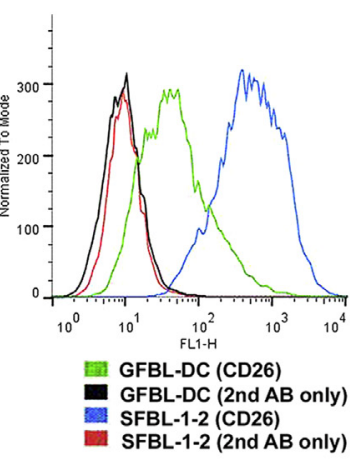

G

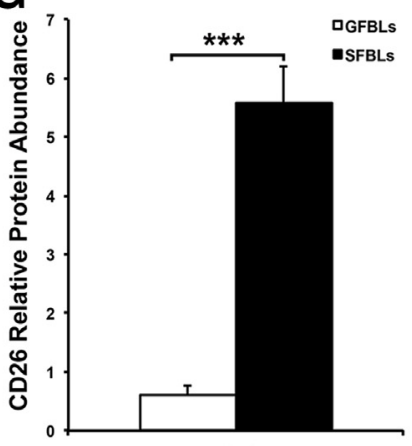

I

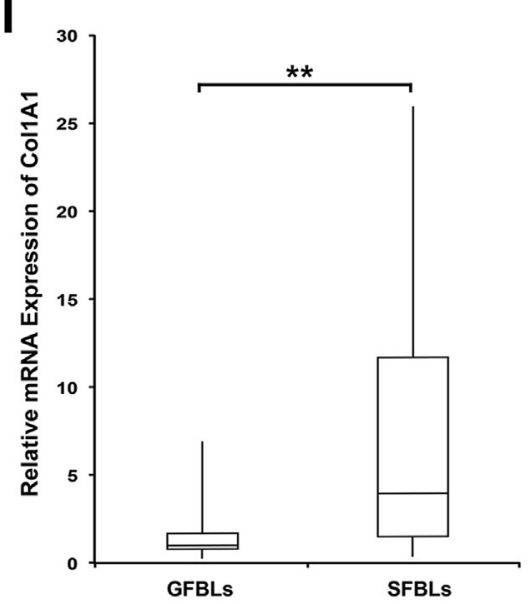

K

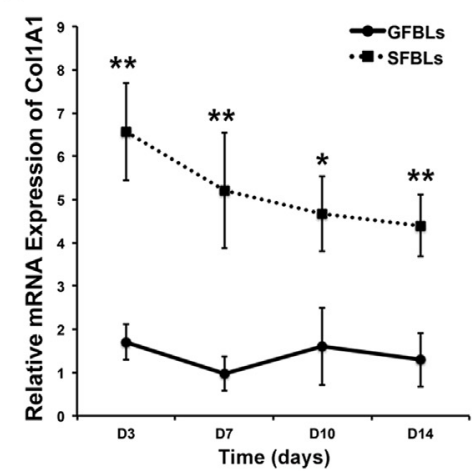

Figure 3 Significantly elevated CD26 abundance in human SFBLs as compared to GFBLs associates with increased type I collagen (Col1A1) expression in 3D cultures. A-G: SFBLs produce significantly higher levels of CD26 than GFBLs. A: Box plot shows quantification of relative immunostaining intensity of CD26 in human gingival (GFBLs) and skin (SFBLs) fibroblast 3D cultures 7 days after seeding. B and C: Representative images of CD26 (red) and nuclear DAPI staining (blue) in SFBL-1-2 (B) and GFBL-DC (C) 3D cultures 7 days after seeding. D: Negative control staining. E: Quantification of CD26 cell surface levels by fluorescence-activated cell sorting analysis in four parallel GFBL and SFBL lines (GFBL-DC, GFBL-OL, GFBL-IE， GFBL-MBe, and SFBL-1-2, SFBL-4-1, SFBL-2-C, SFBL-302). F: Representative results from Western blotting of CD26 from 3D cultures 7 days after seeding from four parallel SFBL and GFBL lines, as indicated. $\beta$-Actin was used as a loading control. CD26 mean relative fluorescence of GFBLs was 1.00 (SEM, 0.313) compared to 3.84 (SEM, $0.633)$ for SFBLS $(P=0.008)$. Quantification of relative CD26 levels from Western blots from 3D cultures from five GFBL (GFBL-DC, GFBL-OL, GFBLDW, GFBL-HN, GFBL-IF) and SFBL (SFBL-1-2, SFBL2-C, SFBL-4-1, SFBL-302, SFBL-406) lines from different donors. G: Results are from two to three repeated experiments. $\mathbf{H}-\mathbf{K}$ : SFBLs express significantly higher levels of CD26 and type I collagen mRNA than GFBLs. Box blots of relative expression of $\mathrm{CD} 26(\mathbf{H})$ and type I collagen (I) mRNA in GFBL and SFBL 3D cultures 7 days after seeding, analyzed by RT-qPCR. Relative mRNA expression of CD26 (J) and type I collagen (K) over time in $3 \mathrm{D}$ cultures. Results arefrom the above five parallel GFBL and SFBL lines. Statistical comparisons between GFBLs and SFBLs were performed by $t$-test (A and $\mathbf{G}-\mathbf{K})$. Data are expressed as means \pm SEM. $n=12$ cell lines (GFBLs, $\mathbf{A}, \mathbf{H}$, and I); $n=9$ cell lines (SFBLs, $\mathbf{A}, \mathbf{H}$, and I). ${ }^{*} P<0.05,{ }^{* *} P<0.01$, and ${ }^{* *} P<0.001$ skin versus gingiva. Scale bar $=100 \mu \mathrm{m}(\mathbf{B}-\mathbf{D})$. AB, antibody. 
CD26 remained significantly elevated in SFBLs compared to GFBLs for up to 14 days after seeding (Figure 3J). The difference in CD26 levels between GFBLs and SFBLs was not significantly affected by the presence or absence of serum in the culture medium, or increase in passage from 3 to 10 (data not shown).

\section{Increased Expression of CD26 in Human SFBLs Associates with a Profibrotic Gene Expression Profile}

The findings from above showed that high CD26 expression distinguishes SFBLs from GFBLs. This difference associates with significantly higher type I collagen expression in SFBLs compared to GFBLs. To assess whether the high CD26 expression in SFBLs is also linked to expression of other wound healing - and fibrosis-related genes, we used a subset of five GFBL (GFBL-DC, GFBL-OL, GFBL-DW, GFBL-HN, GFBL-IF) and SFBL (SFBL-1-2, SFBL-2-C, SFBL-4-1, SFBL-302, SFBL-406) lines from above. We have shown previously that 41 wound healing- and fibrosis-related genes of 65 genes analyzed were significantly differently expressed by these GFBLs and SFBLs in the 3D cultures. ${ }^{26}$ In particular, GFBLs expressed higher levels of genes associated with regulation of inflammation and ECM remodeling [matrix metalloproteinases (MMPs)], whereas SFBLs expressed significantly elevated levels of genes involved in fibrosis and scar formation, including several ECM molecules, TGF- $\beta$ signaling, and myofibroblast- and cell contractility-associated genes. ${ }^{26}$ These properties were not associated with myofibroblast differentiation, as both GFBL and SFBL cultures contained few myofibroblasts, as determined by immunostaining for the $\alpha$ SMA-rich filamentous cytoskeleton. ${ }^{26}$ Also, when levels of CD26 (RT-qPCR, Western blotting, immunostaining, and fluorescence-activated cell sorting) and type I collagen (RTqPCR) for this set of five cell lines were compared separately, SFBLs expressed significantly higher levels of these genes/proteins as compared to GFBLs in all analyses (Supplemental Table S1). Thus, higher expression of CD26 in SFBLs associates with a profibrotic gene expression profile as compared to GFBLs in 3D cultures.

\section{Expression of CD26 Regulates the Phenotype of SFBLs Independent of CD26 Enzymatic Activity}

In addition to serving as a binding protein, receptor, or coreceptor for various ligands, CD26 has catalytic activity targeting a wide range of proline- or alanine-rich substrates. ${ }^{41-43}$ To assess whether CD26 had a functional role in the SFBL phenotype, we treated the 3D cultures with increasing concentrations of two inhibitors of CD26 catalytic activity, diprotin A (0 to $10 \mathrm{mmol} / \mathrm{L}$ ) and sitagliptin ( 0 to $100 \mu \mathrm{mol} / \mathrm{L}$ ), and assessed expression of the above 41 differentially expressed genes after 24 hours. Neither of the inhibitors led to significant changes in the expression of the target genes (data not shown). In addition, inhibition of CD26 by sitagliptin (30 and $100 \mu \mathrm{mol} / \mathrm{L}$ ) did not affect serum-induced growth of SFBLs over 6 days (data not shown). Histochemical staining that detects CD26/DPP4 enzymatic activity performed in the presence or absence of the inhibitors confirmed their functionality (Supplemental Figure S5, B-E).

To assess whether nonenzymatic functions of CD26 regulate SFBL phenotype, we suppressed CD26 expression by two distinct CD26 siRNAs separately or in combination. Analysis by RT-qPCR showed $>90 \%$ down-regulation of CD26 mRNA by the treatments at days 2 and 6 after transfection (Figure 4G).
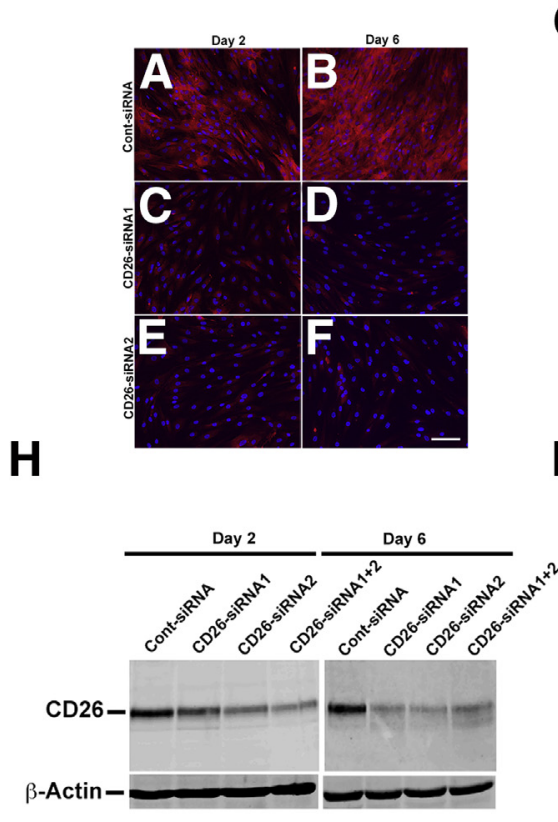

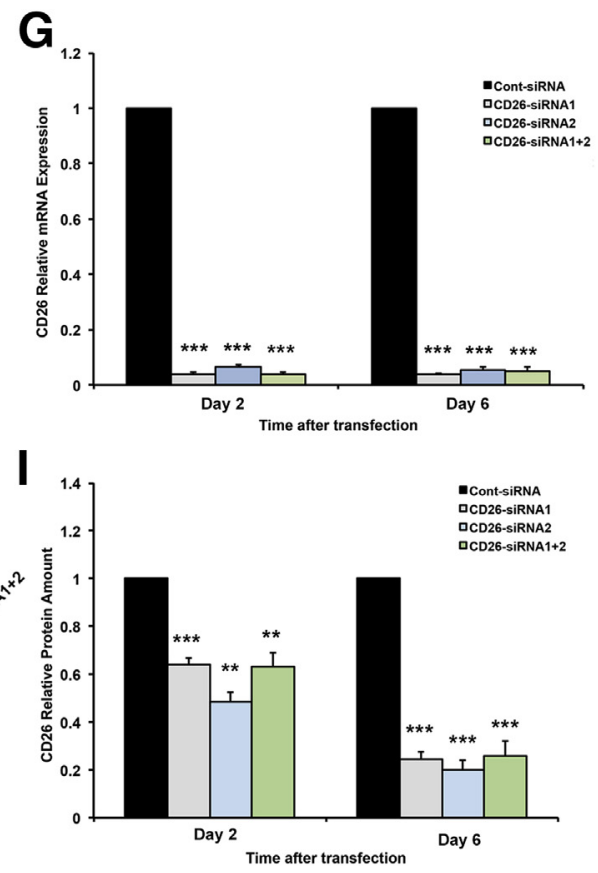

Figure 4 Down-regulation of CD26 in SFBLs by CD26 siRNA transfection over time. A-F: Representative CD26 immunostaining (red) in SFBL-1-2 cell line $2(\mathbf{A}, \mathbf{C}$, and $\mathbf{E})$ and 6 days (B, D, and $\mathbf{F})$ after transfection with control siRNA (A and $\mathbf{B})$, or with CD26-siRNA1 (C and D) or CD26-siRNA2 (E and $\mathbf{F}$ ). Nuclei were stained with DAPI (blue). G: Analysis of CD26 mRNA expression by RT-qPCR 2 and 6 days after transfection with Cont-siRNA, CD26-siRNA1, CD26-siRNA2, or a combination of CD26-siRNA1+2. H: Representative Western blotting analysis of CD26 levels 2 and 6 days after CD26 siRNA transfection in SFBL-4-1. $\beta$-Actin was used as a loading control. I: Quantification of CD26 Western blotting at days 2 and 6 after CD26-siRNA transfection. Results were normalized for $\beta$-actin levels in the same blots. Results are from four SFBL lines (SFBL-1-2, SFBL-4-1, SFBL03, SFBL-20) relative to Cont-siRNA treated cells $(=1)$ (G and I). Pairwise statistical comparison to Cont-siRNA-treated samples was performed by $t$-test. Data are expressed as means \pm SEM ( $G$ and I). ${ }^{* *} P<0.01,{ }^{* * *} P<0.001$ versus Cont-siRNA. Scale bar $=50 \mu \mathrm{m}(\mathbf{A}-\mathbf{F})$. 
Immunostaining and immunoblotting of CD26 showed also a robust down-regulation of $\mathrm{CD} 26$ protein by the siRNA treatments (Figure 4, A-F, H, and I). CD26 protein levels were reduced by $36 \%$ to $51 \%$ and $74 \%$ to $80 \%$ at days 2 and 6, respectively (Figure 4I). CD26 siRNA treatment did not significantly affect serum-induced SFBL growth over 6 days (data not shown). In contrast, RTqPCR analysis of the above 41 genes showed a significant change $(P<0.05)$ in expression of $29(71 \%)$ of genes at day 2 after transfection by the CD26-siRNA treatment relative to Cont-siRNA treatment (Figure 5 and Supplemental Table S2). In particular, genes involved in ECM remodeling and immunomodulation ( $M M P 1$, $M M P 3, M M P 7$, and MMP10) and genes encoding TGF$\beta R$ I, TGF- $\beta$ RII, and antifibrotic TGF- $\beta 3$ were upregulated. In contrast, several genes associated with ECM deposition (types I and III collagen, biglycan, elastin-1, tenascin- $\mathrm{C}$ and tenascin- $\mathrm{X}$, thrombospondin-1 and thrombospondin-2, and connective tissue growth factor (CTGF; alias CCN2) and cell contractility and myofibroblast phenotype ( $\alpha$-SMA, $\alpha 11$ integrin, cadherin2 , cadherin 11, and non-muscle myosin IIA and IIB) were down-regulated. Thus, high expression of CD26, but not its catalytic activity, regulates the profibrotic phenotype of SFBLs.

\section{CD26 Modulates TGF- $\beta$ Signaling in SFBLs}

Previous studies have suggested increased profibrotic autogenous TGF- $\beta$ signaling in SFBLs compared to GFBLs. ${ }^{21-23}$ Our previous data also showed that phosphorylated SMAD3 (p-SMAD3), relative to total SMAD3, along with several genes involved in TGF- $\beta$ signaling were significantly more highly expressed by human SFBLs as compared to GFBLs in the 3D cultures. ${ }^{26}$ Therefore, we next explored in more detail how the TGF- $\beta$ signaling pathway was linked to the phenotype of SFBLs. We first assessed steady-state levels of p-SMAD3 relative to total SMAD3 in serum-starved human GFBL and SFBL 3D cultures by Western blotting. Results showed an almost threefold higher amount of p-SMAD3 relative to total SMAD3 in SFBLs compared to GFBLs (Supplemental Figure S6, A and B). Blocking of CD26 catalytic activity with sitagliptin (5 and $100 \mu \mathrm{mol} / \mathrm{L}$ ) for 24 hours did not significantly affect the relative p-SMAD3/total SMAD3 levels (data not shown). In contrast, down-regulation of CD26 expression by siRNA resulted in a significant increase of p-SMAD3 and total SMAD3 levels in SFBLs (Figure 6, $A$ and $B$ ). In contrast, SMAD3 mRNA levels were not significantly changed (Figure 6C), suggesting that CD26 silencing increased the stability of SMAD3 proteins. Thus, CD26 expression, but not its catalytic activity, is linked to modulation of the levels of p-SMAD3 and total SMAD3 in SFBLs.

To also explore whether TGF- $\beta$ signaling regulates CD26 expression and the profibrotic SFBL phenotype

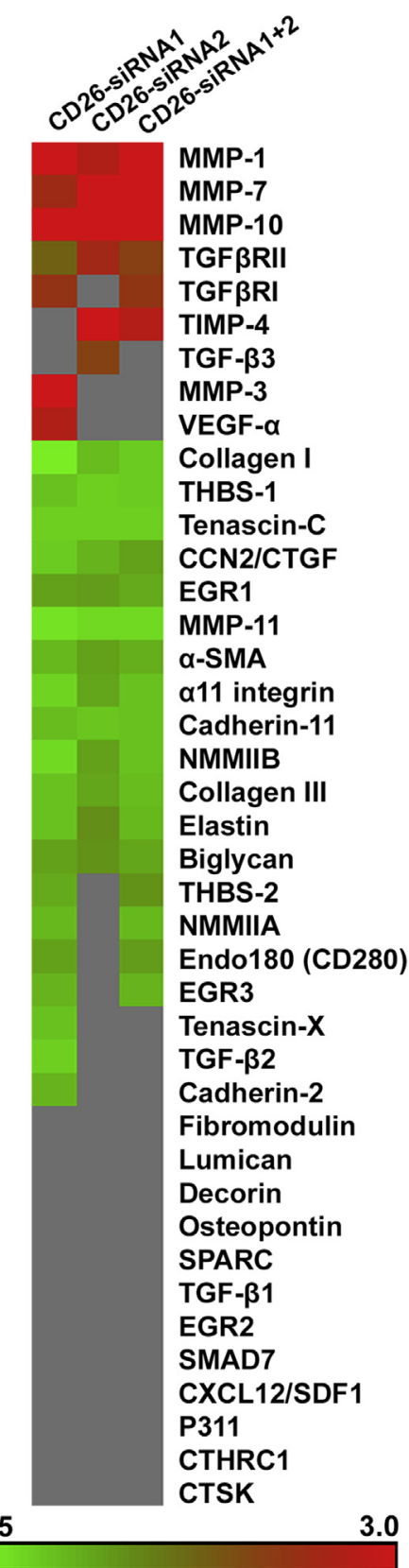

Figure 5 Down-regulation of CD26 mRNA expression by CD26-siRNA regulates expression of a set of fibrosis-related genes highly expressed in human SFBLs. Table shows RT-qPCR analysis of mRNA expression in SFBL cultures treated with $30 \mathrm{nmol} / \mathrm{L}$ CD26-siRNA1, $30 \mathrm{nmol} / \mathrm{L}$ CD26-siRNA2, or CD26-siRNA1+2 (15 nmol/L each) relative to control siRNA-treated samples $(=1) 2$ days after transfection. Results are from four SFBL lines (SFBL-1-2, SFBL-4-1, SFBL-02, SFBL-30). Pairwise statistical comparison between CD26siRNA and Cont-siRNA treatments was performed by $t$-test. Green indicates statistically significant $(P<0.05)$ down-regulation; red, up-regulation; and gray, no change in gene expression by CD26-siRNA treatment relative to Cont-siRNA. Analysis was focused on the 41 genes significantly more highly expressed in SFBLs compared to GFBLs. ${ }^{26}$ CCN2/CTGF, connective tissue growth factor; CTHRC1, collagen triple-helix repeat containing 1; CTSK, cathepsin K; CXCL12, alias stromal-derived factor $1 \alpha$ (SDF-1 $\alpha$ ); EGR1, EGR2, and EGR3, early growth response 1, 2, and 3; NMMIIA and NMMIIB, non-muscle myosin IIA and IIB; $\alpha$-SMA, $\alpha$-smooth muscle actin; SPARC, secreted protein acidic and rich in cysteine; TGF- $\beta$ RI and TGF- $\beta$ RII, TGF- $\beta$ receptors I and II; THBS, thrombospondin; TIMP, tissue inhibitor of metalloproteinases; VEGF $\alpha$, vascular endothelial growth factor- $\alpha$. 

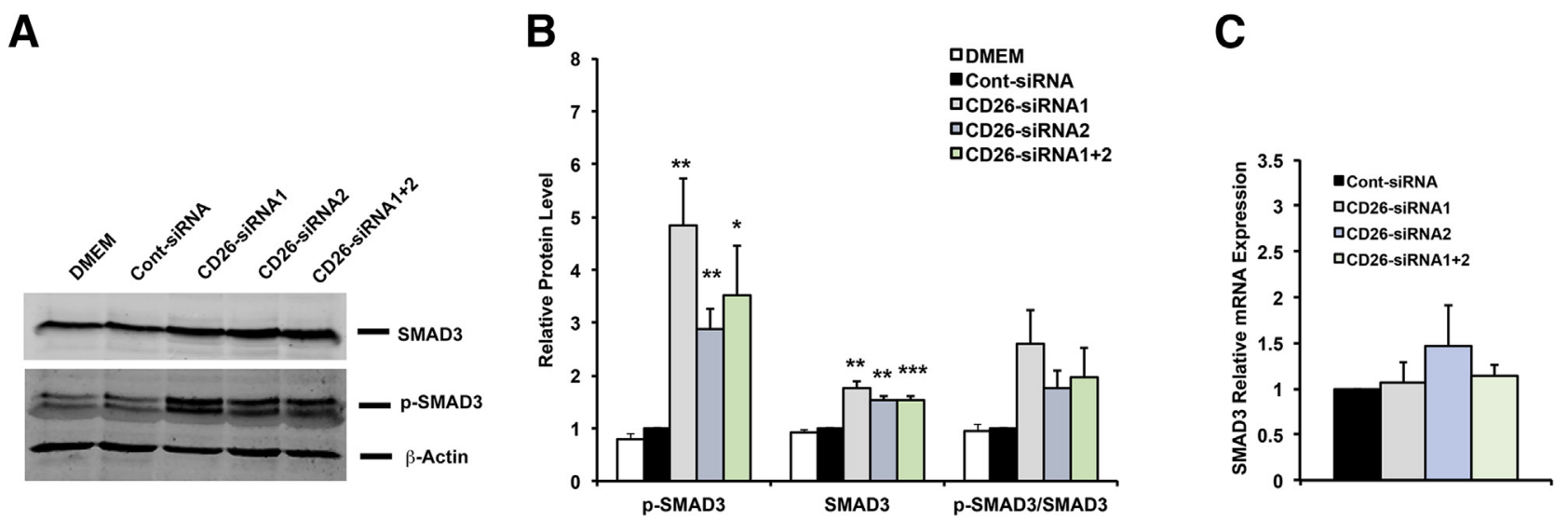

Figure 6 Down-regulation of CD26 by siRNA promotes transforming growth factor (TGF)- $\beta$ signaling in SFBLs. A: Representative Western blotting of total SMAD3 and p-SMAD3 in SFBL-4-1 culture 2 days after transfection with Cont-siRNA, CD26-siRNA1, CD26siRNA2, or CD26-siRNA1+2. Dulbecco's modified Eagle's medium (DMEM), nontransfected control samples. $\beta$-actin was used as loading control. For the experiments, cells were cultured in their normal growth medium for 2 days after siRNA transfection. B: Quantification of p-SMAD3 and total SMAD3 abundance in Western blots from four parallel SFBL lines (SFBL-1-2, SFBL-41, SFBL-03, SFBL-20) treated as above. C: Quantification of SMAD3 mRNA levels by RT-qPCR in the above four SFBL lines 2 days after transfection, as above. Statistical comparisons were performed relative to Cont-siRNA-treated samples. Data are expressed as means $\pm \operatorname{SEM}(\mathbf{B}$ and $\mathbf{C})$. ${ }^{*} P<0.05, * * P<0.01$, and $* * * P<0.001$ versus Cont-siRNA ( $t$-test).

(Supplemental Figure S6, A-G), we treated serumstarved SFBL cultures with SB-431542, a TGF- $\beta$ receptor inhibitor. ${ }^{63}$ The inhibitor blocked p-SMAD3 activation by approximately 55\% in both GFBLs and SFBLs (Supplemental Figure S6, A and C) and resulted in a significant down-regulation of type I collagen mRNA expression (by approximately 40\%) in SFBLs but not in GFBLs (Supplemental Figure S6G). In addition, analysis of the above 41 genes in SFBLs showed that $28(68 \%)$ of them displayed significantly altered expression after SB431542 treatment (Supplemental Tables S3 and S4), indicating that the profibrotic SFBL phenotype is also partially regulated by increased autogenous TGF- $\beta$ signaling. However, SB-431542 treatment had no effect on the expression of CD26 (Supplemental Figure S6E).

To further test whether exogenous TGF- $\beta$ regulates CD26 levels, we treated GFBL and SFBL 3D cultures with increasing concentrations of recombinant TGF- $\beta 1$ and TGF$\beta 3$ ( 0 to $50 \mathrm{ng} / \mathrm{mL}$ ), two TGF- $\beta$ isoforms with partially distinct properties. ${ }^{6,64}$ Neither of the TGF- $\beta$ isoforms had a significant effect on the expression of CD26 in GFBLs and SFBLs (Supplemental Figure S6, H and I), although there was a trend of reduced CD26 expression with increasing concentrations of TGF- $\beta 1$ in SFBLs. In contrast, both TGF$\beta 1$ and TGF- $\beta 3$ caused a significant dose-dependent increase in type I collagen mRNA expression compared to non-treated cultures in SFBLs, as expected, whereas in GFBLs, only the increase resulting from TGF- $\beta 1$ treatment was statistically significant (Supplemental Figure S6, J and $\mathrm{K})$. A minimum of twofold increases in type I collagen expression were achieved by $5 \mathrm{ng} / \mathrm{mL}$ of TGF- $\beta 1$ in GFBLs, whereas SFBLs required $>20 \mathrm{ng} / \mathrm{mL}$ to reach this threshold (Supplemental Figure S6L). A similar trend was also observed with TGF- $\beta 3$ treatment (Supplemental
Figure S6M). Thus, unlike type I collagen, expression of CD26 is not regulated by exogenous TGF- $\beta 1$ or TGF- $\beta 3$ in GFBLs and SFBLs.

Taken together, SFBLs display increased CD26 expression that regulates their profibrotic phenotype and TGF- $\beta$ signaling. Although autogenous TGF- $\beta$ signaling drives expression of several profibrotic genes in SFBLs, it does not regulate CD26 levels.

Expression of CD26 in SFBLs Does Not Depend on the 3D ECM Niche

Cell- and tissue-specific niche is a powerful regulator of cell phenotype, differentiation, and gene expression both in vivo and in vitro. ${ }^{31}$ Therefore, we tested whether the 3D ECM niche produced by GFBLs and SFBLs could determine their phenotype. To this end, we generated decellularized 3D ECMs from GFBLs and SFBLs, and then reseeded the cells into these ECMs in homotypic and heterotypic combinations. The cells were also seeded on two-dimensional collagen-coated control substrates. We have shown previously that GFBLs and SFBLs produce a distinct, cell type-specific 3D ECM in this model. ${ }^{26}$ The cultures were then compared to the standard 7-day 3D cultures by RT-qPCR and Western blotting. Results showed that similar to findings in standard 3D cultures, SFBLs displayed markedly increased expression of $\mathrm{CD} 26$ and type I collagen (Supplemental Figure S7, D and E, respectively) and pSMAD3/total SMAD3 levels (Supplemental Figure S7, A-C) compared to GFBLs, irrespective of the ECM substrate that the cells were seeded into. In contrast, MMP-10 and TGF- $\beta 2$, two genes significantly more highly expressed by GFBLs in 3D cultures (by approximately 16and 7-fold, $P<0.01$ and $P<0.05$, respectively), lost this 
difference when cells were reseeded into these ECMs (Supplemental Figure S7, F-H). Thus, unlike MMP-10 and TGF- $\beta 2$, increased expression of CD26 and type I collagen and activation of autogenous TGF- $\beta$ signaling in SFBLs compared to GFBLs are independent of the ECM niche in the $3 \mathrm{D}$ cultures.

\section{Discussion}

Findings from mesodermal lineage-specific Enl-reporter mice have indicated that a fibroblast subpopulation that can be prospectively identified by high CD26 expression comprises approximately $70 \%$ of fibroblasts in adult dorsal skin. This subpopulation is also responsible for the profibrotic tissue response and fibrosis in the skin of these animals. ${ }^{12}$ In contrast, findings from neural crest-specific Wntl-reporter mice have shown that approximately $90 \%$ of the oral mucosal connective tissue cells derive from the neural crest, although oral mucosa also contains a small population of mesodermal-derived cells. $^{37}$ Furthermore, the neural crest-derived cells in mouse oral mucosa display an attenuated profibrotic phenotype compared to the mesodermal CD26-expressing skin fibroblast population. ${ }^{12}$ Thus, the previously observed less fibrotic wound-healing response in oral mucosa, as compared to skin, in various animal models and humans ${ }^{7,10,11}$ may depend on the lack of the profibrotic CD26-positive population and/or, in general, a distinct phenotype of the oral mucosal cells. To explore this, we first compared the presence and localization of CD26-positive fibroblasts in hypertrophic-like scar-forming skin and scarless oral mucosal gingival wounds in red Duroc pigs. ${ }^{7}$ As expected, based on both histochemical and CD26 immunostaining, nonwounded skin contained numerous CD26-positive cells that had the typical fibroblast morphology. These cells were abundant in the papillary dermis, but present also in the reticular dermis, as has been previously found in adult mice. ${ }^{24}$ Double immunostaining of human skin samples with CD26 antibody and different cell type markers, and staining of cultured fibroblasts for CD26, confirmed the localization of CD26 to fibroblasts. Strikingly, during skin wound healing in pigs, CD26positive cells became abundant in distinct tissue compartments (ie, in the connective tissue next to the wound, around hair follicles, and in adipose tissue), and then accumulated in the forming hypertrophic-like scar. Various genetic tools for lineage tracing have previously indicated the above tissue compartments as sources of cell populations that participate in wound healing, and they also contain CD26positive cells in mouse skin. ${ }^{4,16,44}$ It is, therefore, possible that wounding induced an increased expression of CD26 in resident cells and/or the CD26-positive population already present in the tissue was recruited to expand. Our cell culture data, showing that CD26 levels in fibroblasts are not affected by different factors present in wounds (ie, serum, TGF- $\beta$ signaling, or change in ECM niche) suggest the latter option to be plausible. It is also unlikely that increases in CD26 expression were directly induced by the acute wounding-induced inflammatory reaction, as the highly CD26-positive connective tissue cells appeared at the later stages of wound healing when the inflammation phase was already down-regulated (days 14 and 28). In addition, mRNA analysis data of wounds from the same animals did not show significant differences in total CD26 expression between nonwounded tissue and different stages of wound healing, granted that gene expression analysis cannot explicitly confirm whether CD26 mRNA levels may have changed among different cell populations. In any case, the end result was accumulation of CD26-positive cells throughout the forming scars at day 28, and these cells persisted in the tissue when the hypertrophic-like scars were formed at day 60 after wounding. ${ }^{7}$ Therefore, the findings suggest that the CD26-positive skin fibroblast population, likely originating from distinct tissue compartments around the wound, is involved in pathological scar formation in a model that closely mimics the human situation., ${ }^{8,45,46}$

In contrast to skin, gingiva in the pigs and humans contained few CD26-positive fibroblasts, and the CD26 immunoreactivity that was noted associated mostly with vasculature and inflammatory cells. Comparable cellular CD26/DPP4 localization has also been described previously in inflamed human gingiva using histochemical staining. ${ }^{65}$ Accordingly, analysis of pig gingiva showed approximately $80 \%$ lower expression of CD26 mRNA than skin. Based on mouse studies, oral mucosal connective tissue may contain only approximately $10 \%$ of cells that are of mesenchymal origin, whereas the rest of the cells derive from the neural crest. ${ }^{37}$ The rarity of CD26-positive fibroblasts in gingiva, therefore, suggests that neural crest-derived fibroblasts do not express this marker at a level that is detectable by immunostaining in vivo.

During gingival wound healing, there was a significant increase in CD26 mRNA expression at days 3 and 14 after wounding. At this stage, CD26 was most abundantly present in inflammatory cells and forming blood vessels at the wound margin and granulation tissue. Our previous analysis of CD26/DPP4 staining in human 3- and 7-day gingival wounds has also shown comparable findings. ${ }^{41}$ Interestingly, however, some CD26-positive fibroblast-like cells also transiently appeared in the gingival wounds at days 14 and 28. This is in line with previous findings in mice showing that among oral mucosal cells, the CD26expressing population is involved in ECM deposition during wound healing. ${ }^{24}$ The origin of this CD26-positive population in gingival wounds remains unclear. One possibility is that CD26-positive cells transiently present in gingival wounds expand from the small potentially mesoderm-derived population that may be present in the tissue. Alternatively, the wound microenvironment may induce CD26 expression by GFBLs. These intriguing possibilities remain to be further explored. In any case, unlike in pig skin wounds, the CD26-positive connective tissue cell 
population had disappeared by day 60 from regenerated gingival wounds. Thus, CD26-positive connective tissue cells may play a temporary role in the granulation tissue formation and remodeling stage of gingival wound healing, whereas in skin wounds, they accumulate and persist, resulting in scar formation.

The cell culture findings showed that, like in vivo, human GFBL 3D cultures displayed significantly lower levels of CD26 than corresponding SFBL cultures. Given that human gingival and fetal skin fibroblasts share certain phenotypic features, ${ }^{27,29}$ it is interesting that human adult SFBLs display also severalfold higher CD26/DPP4 enzymatic activity than human embryonic skin fibroblasts. ${ }^{66}$ Curiously, although fibroblasts in nonwounded gingiva in vivo showed little CD26 immunoreactivity, cultured GFBLs showed some CD26 mRNA and cell surface expression. It is possible that low CD26 levels are not as readily detectable in vivo than in vitro. Another possibility is that cell culture selected a rare population of GFBLs from tissue with a higher CD26 level. In addition, rather than mimicking the steady-state situation in nonwounded tissue, propagation of the cells for culture could introduce a wound-like effect that involves cell proliferation, migration, and exposure to serum. In any case, the findings showed that, in cell culture, the difference in CD26 levels between GFBLs and SFBLs was stable and not affected by culture time, passaging, serum, TGF- $\beta$ signaling, or cell type-specific ECM niche. Hence, expression of CD26 may be determined by cellintrinsic properties of GFBLs and SFBLs rather than external factors. Our further analysis of a set of woundhealing-related genes in the 3D culture model showed that this SFBL phenotype also associated with a profibrotic gene expression profile that was distinct from GFBLs. In addition, silencing of CD26 expression by siRNA in SFBLs caused a significant down-regulation of the expression of several ECM proteins, including type I collagen, and cell contractility- and myofibroblast-associated genes, and increased expression of MMPs involved in ECM remodeling and regulation. ${ }^{67}$ Thus, CD26 silencing attenuated the profibrotic gene expression profile of SFBLs. This attenuated SFBL phenotype resembles the gene expression profile of GFBLs, which displays inherently lower expression of CD26 and the above profibrotic genes and a higher expression of several MMPs compared to SFBLs. ${ }^{26}$

TGF- $\beta$ signaling has been long linked to profibrotic tissue responses and pathological scar formation. ${ }^{1,2}$ Our previous findings showed that hypertrophic-like scars formed in skin of the red Duroc pigs used in the present study contained significantly higher numbers of TGF- $\beta$ and p-SMAD3-positive connective tissue cells as compared to gingival wounds at day 60 after wounding. ${ }^{7}$ Increased autogenous TGF- $\beta$ signaling has also been associated with SFBL phenotype over GFBLs in standard two-dimensional cultures. ${ }^{21-23}$ Our similar results from experiments comparing GFBLs and SFBLs in 3D cultures emphasize the relevance of these findings. The present study also suggests that this phenotype is inherent to SFBLs and does not depend on the tissue-specific in vivo-like 3D ECM niche. A series of elegant experiments has linked the propagated SFBL response to TGF- $\beta 1$ to higher endothelin- 1 , focal adhesion kinase, and miR-2018 expression. ${ }^{21-23}$ Our findings show that SFBLs also express significantly increased levels of several positive regulators of TGF- $\beta$ signaling. Expression of many of these molecules was down-regulated by blocking of autogenous TGF- $\beta$ signaling using SB-431542, which suggests that their expression in SFBLs was under the control of this pathway, possibly via a positive feedback loop. These genes include TGF- $\beta 1$ and TGF- $\beta 3$ isoforms, thrombospondin-1 (an activator of latent TGF- $\beta^{68}$ ), early growth response 1,2 , and 3 (three transcriptional regulators of TGF- $\beta$ signaling targets highly expressed in fibrosis ${ }^{69-71}$ ), and P311 (a positive regulator of TGF- $\beta$ translation ${ }^{72}$ ). However, increased activation of the autogenous TGF- $\beta$ pathway or exogenously added TGF- $\beta$ did not regulate expression of CD26 in SFBLs. In contrast, silencing of CD26 in SFBLs by siRNA resulted in a significant increase in mRNA expression of TGF- $\beta$ RI, TGF- $\beta$ RII, and TGF- $\beta 3$ (a cytokine that, unlike other TGF- $\beta$ isoforms, has contextdependent antifibrotic or profibrotic effects ${ }^{73}$ ) and resulted in significantly increased p-SMAD3 and SMAD3 protein levels. Paradoxically, although CD26 silencing up-regulated TGF- $\beta$ signaling, at the same time, certain molecules, including type I collagen, elastin-1, and tenascin-C, that are up-regulated in SFBLs via TGF- $\beta$ signaling were significantly down-regulated. This suggests that regulation of the SFBL profibrotic phenotype by CD26 and TGF- $\beta$ signaling may be mediated by a complex interplay between these pathways that should be further investigated.

The role of myofibroblasts in organ fibrosis has been well established based on studies showing that they accumulate in the lesions and are responsible for the excess production of ECM. During normal skin or mucosal wound healing, myofibroblasts also temporarily participate in wound contraction and production of ECM. ${ }^{57}$ It has been proposed that persistence of these cells beyond what is needed for normal wound healing will lead to pathological scarring. However, the exact role of myofibroblasts in this process has remained less clear as they can be found only irregularly in both hypertrophic scars and keloids. ${ }^{74-76}$ Therefore, the finding that the presence of $\mathrm{CD} 26$ in wound connective tissue cells only partially overlapped that of $\alpha$-SMA, a myofibroblast marker, in both gingival and skin wounds is interesting. Most important, in established hypertrophic-like scars in pig skin, where myofibroblasts were largely absent, CD26-positive fibroblasts accumulated at the fibrotic areas. In contrast, less scar-forming gingival wounds still contained myofibroblasts, ${ }^{7}$ but were devoid of CD26-positive cells. Thus, CD26 expression appears to define a profibrotic fibroblast population distinct from myofibroblasts and may be more critical for pathological scar formation.

Unlike CD26 siRNA treatment, blocking of CD26 catalytic activity with diprotin A or sitagliptin in 3D cultures did 
not regulate the distinct phenotype of GFBLs and SFBLs. This is in contrast to findings from a mouse skin fibrosis model in vivo, where application of diprotin A attenuated the fibrotic tissue response. ${ }^{12}$ Other inhibitors of CD26 catalytic activity, including sitagliptin, have also reduced organ fibrosis (eg, in kidney, heart, and liver). ${ }^{43,52}$ It is likely, that in different tissues and models, CD26 may have a context-specific function. For instance, the noted antifibrotic effect of CD26 inhibitors may depend on their ability to inhibit CD26-mediated inflammatory cytokine and chemokine degradation and on their cell-specific effects on different cell types, including inflammatory and endothelial cells, which contribute to fibrosis. ${ }^{43,77}$ Furthermore, structurally distinct inhibitors of CD26 catalytic activity may also differently influence certain cell type-specific nonenzymatic functions of CD26. ${ }^{78}$ Clearly, the enzymatic and nonenzymatic functions of fibroblast CD26 in tissue fibrosis need further clarification.

The involvement of $\mathrm{CD} 26^{+}$fibroblasts in the profibrotic tissue response in dorsal skin has been elegantly shown in mouse models. ${ }^{12,41-43}$ Our findings that compared scar formation in red Duroc pig gingiva and dorsal skin further support the role of $\mathrm{CD} 26^{+}$fibroblasts in the profibrotic response in a model that mimics human skin wound healing and scar formation. ${ }^{79} \mathrm{We}$ also showed that CD26 was highly expressed in human ventral (abdominal and breast) dermis and corresponding SFBLs, and that this associated with a profibrotic SFBL phenotype compared with GFBLs. Ventral and dorsal dermal fibroblasts have a distinct mesodermal developmental origin. ${ }^{80}$ Furthermore, SFBLs from these two skin locations in red Duroc pigs have certain functional differences. ${ }^{81}$ Therefore, the phenotype of human dorsal SFBLs needs to be further explored.

To summarize, the findings indicate that SFBLs present in human normal, nonwounded tissue compose an inherently distinct and stable phenotype characterized by a markedly higher expression of CD26 than GFBLs. The CD26-expressing SFBLs accumulated and persisted in skin during pathological scar formation and appeared distinct from myofibroblasts. High CD26 expression in SFBLs associated with a distinct wound healing-related profibrotic gene expression profile, which was partially regulated by CD26 expression independent of its catalytic activity. This CD26-associated profibrotic pathway was involved in regulation of TGF- $\beta$ signaling, another key profibrotic pathway, in these cells. Thus, CD26 may serve as a profibrotic fibroblast marker that regulates the profibrotic SFBL phenotype, providing a novel target to alleviate fibrosis and scar formation.

\section{Supplemental Data}

Supplemental material for this article can be found at http://dx.doi.org/10.1016/j.ajpath.2017.04.017.

\section{References}

1. Durani P, Occleston N, O'Kane S, Ferguson MW: Avotermin: a novel antiscarring agent. Int J Low Extrem Wounds 2008, 7:160-168

2. Gauglitz GG, Korting HC, Pavicic T, Ruzicka T, Jeschke MG: Hypertrophic scarring and keloids: pathomechanisms and current and emerging treatment strategies. Mol Med 2011, 17:113-125

3. Greaves NS, Ashcroft KJ, Baguneid M, Bayat A: Current understanding of molecular and cellular mechanisms in fibroplasia and angiogenesis during acute wound healing. J Dermatol Sci 2013, 72 : 206-217

4. Leavitt $\mathrm{T}$, Hu MS, Marshall CD, Barnes LA, Lorenz HP, Longaker MT: Scarless wound healing: finding the right cells and signals. Cell Tissue Res 2016, 365:483-493

5. Sciubba JJ, Waterhouse JP, Meyer J: A fine structural comparison of the healing of incisional wounds of mucosa and skin. J Oral Pathol 1978, 7:214-227

6. Szpaderska AM, Zuckerman JD, DiPietro LA: Differential injury responses in oral mucosal and cutaneous wounds. J Dent Res 2003, $82: 621-626$

7. Mak K, Manji A, Gallant-Behm C, Wiebe C, Hart DA, Larjava H, Häkkinen L: Scarless healing of oral mucosa is characterized by faster resolution of inflammation and control of myofibroblast action compared to skin wounds in the red Duroc pig model. J Dermatol Sci 2009, 56:168-180

8. Wong JW, Gallant-Behm C, Wiebe C, Mak K, Hart DA, Larjava H, Häkkinen L: Wound healing in oral mucosa results in reduced scar formation as compared with skin: evidence from the red Duroc pig model and humans. Wound Repair Regen 2009, 17:717-729

9. Chen L, Arbieva ZH, Guo S, Marucha PT, Mustoe TA, DiPietro LA: Positional differences in the wound transcriptome of skin and oral mucosa. BMC Genomics 2010, 11:471

10. Larjava H, Wiebe C, Gallant-Behm C, Hart DA, Heino J, Häkkinen L: Exploring scarless healing of oral soft tissues. J Can Dent Assoc 2011, 77:b18

11. Glim JE, van Egmond M, Niessen FB, Everts V, Beelen RH: Detrimental dermal wound healing: what can we learn from the oral mucosa? Wound Repair Regen 2013, 21:648-660

12. Rinkevich Y, Walmsley GG, Hu MS, Maan ZN, Newman AM, Drukker M, Januszyk M, Krampitz GW, Gurtner GC, Lorenz HP, Weissman IL, Longaker MT: Skin fibrosis: identification and isolation of a dermal lineage with intrinsic fibrogenic potential. Science 2015, 348:aaa2151

13. Häkkinen L, Larjava H, Koivisto L: Granulation tissue formation and remodeling. Endodontic Topics 2012, 24:94-129

14. Tschumperlin DJ: Fibroblasts and the ground they walk on. Physiology (Bethesda) 2013, 28:380-390

15. Zhu J, Clark RA: Fibronectin at select sites binds multiple growth factors and enhances their activity: expansion of the collaborative ECM-GF paradigm. J Invest Dermatol 2014, 134:895-901

16. Driskell RR, Watt F: Understanding fibroblast heterogeneity in the skin. Trends Cell Biol 2015, 25:92e9

17. Zhu Z, Ding J, Shankowsky HA, Tredget EE: The molecular mechanism of hypertrophic scar. J Cell Commun Signal 2013, 7:239-252

18. Sriram G, Bigliardi PL, Bigliardi-Qi M: Fibroblast heterogeneity and its implications for engineering organotypic skin models in vitro. Eur J Cell Biol 2015, 94:483-512

19. Chang HY, Chi JT, Dudoit S, Bondre C, van de Rijn M, Botstein D, Brown PO: Diversity, topographic differentiation, and positional memory in human fibroblasts. Proc Natl Acad Sci U S A 2002, 99: $12877-12882$

20. Dang C, Ting K, Soo C, Longaker MT, Lorenz HP: Fetal wound healing current perspectives. Clin Plast Surg 2003, 30:13-23

21. Guo F, Carter DE, Leask A: Mechanical tension increases CCN2/CTGF expression and proliferation in gingival fibroblasts via a TGFß-dependent mechanism. PLoS One 2011, 6:e19756 
22. Guo F, Carter DE, Mukhopadhyay A, Leask A: Gingival fibroblasts display reduced adhesion and spreading on extracellular matrix: a possible basis for scarless tissue repair? PLoS One 2011, 6:e27097

23. Guo F, Carter DE, Leask A: miR-218 regulates focal adhesion kinasedependent TGF $\beta$ signaling in fibroblasts. Mol Biol Cell 2014, 25: $1151-1158$

24. Driskell RR, Lichtenberger BM, Hoste E, Kretzschmar K, Simons BD, Charalambous M, Ferron SR, Herault Y, Pavlovic G, Ferguson AC, Watt FM: Distinct fibroblast lineages determine dermal architecture in skin development and repair. Nature 2013, 504: 277-281

25. Häkkinen L, Larjava H, Fournier BP: Distinct phenotype and therapeutic potential of gingival fibroblasts. Cytotherapy 2014, 16: $1171-1186$

26. Mah W, Jiang G, Olver D, Cheung G, Kim B, Larjava H, Häkkinen L: Human gingival fibroblasts display a non-fibrotic phenotype distinct from skin fibroblasts in three-dimensional cultures. PLoS One 2014, 9:e90715

27. Schor SL, Ellis I, Irwin CR, Banyard J, Seneviratne K, Dolman C, Gilbert AD, Chisholm DM: Subpopulations of fetal-like gingival fibroblasts: characterisation and potential significance for wound healing and the progression of periodontal disease. Oral Dis 1996, 2: $155-166$

28. Fournier BP, Larjava H, Häkkinen L: Gingiva as a source of stem cells with therapeutic potential. Stem Cells Dev 2013, 22:3157-3177

29. Glim JE, Everts V, Niessen FB, Ulrich MM, Beelen RH: Extracellular matrix components of oral mucosa differ from skin and resemble that of foetal skin. Arch Oral Biol 2014, 59:1048-1055

30. Nishi H, Ohta K, Takechi M, Yoneda S, Hiraoka M, Kamata N: Wound healing effects of gingival fibroblasts cultured in animal-free medium. Oral Dis 2010, 16:438-444

31. Parker MW, Rossi D, Peterson M, Smith K, Sikström K, White ES, Connett JE, Henke CA, Larsson O, Bitterman PB: Fibrotic extracellular matrix activates a profibrotic positive feedback loop. J Clin Invest 2014, 124:1622-1635

32. Marinkovic M, Block TJ, Rakian R, Li Q, Wang E, Reilly MA, Dean DD, Chen XD: One size does not fit all: developing a cellspecific niche for in vitro study of cell behavior. Matrix Biol 2016, $54: 426-441$

33. Rinn JL, Bondre C, Gladstone HB, Brown PO, Chang HY: Anatomic demarcation by positional variation in fibroblast gene expression programs. PLoS Genet 2006, 2:e119

34. Enoch S, Peake MA, Wall I, Davies L, Farrier J, Giles P, Kipling D, Price P, Moseley R, Thomas D, Stephens P: "Young" oral fibroblasts are geno/phenotypically distinct. J Dent Res 2010, 89:1407-1413

35. Miyoshi K, Horiguchi T, Tanimura A, Hagita H, Noma T: Gene signature of human oral mucosa fibroblasts: comparison with dermal fibroblasts and induced pluripotent stem cells. Biomed Res Int 2015, 2015:121575

36. Marynka-Kalmani K, Treves S, Yafee M, Rachima H, Gafni Y, Cohen MA, Pitaru S: The lamina propria of adult human oral mucosa harbors a novel stem cell population. Stem Cells 2010, 28:984-995

37. Xu X, Chen C, Akiyama K, Chai Y, Le AD, Wang Z, Shi S: Gingivae contain neural-crest- and mesoderm-derived mesenchymal stem cells. J Dent Res 2013, 92:825e32

38. Fournier BP, Loison-Robert LS, Ferré FC, Owen GR, Larjava H, Häkkinen L: Characterisation of human gingival neural crest-derived stem cells in monolayer and neurosphere cultures. Eur Cell Mater 2016, 31:40-58

39. Biernaskie J, Paris M, Morozova O, Fagan BM, Marra M, Pevny L, Miller FD: SKPs derive from hair follicle precursors and exhibit properties of adult dermal stem cells. Cell Stem Cell 2009, 5: 610-623

40. Driskell RR, Clavel C, Rendl M, Watt FM: Hair follicle dermal papilla cells at a glance. J Cell Sci 2011, 124:1179-1182

41. Ghersi G, Dong H, Goldstein LA, Yeh Y, Häkkinen L, Larjava HS, Chen WT: Regulation of fibroblast migration on collagenous matrix by a cell surface peptidase complex. J Biol Chem 2002, 277: 29231-29241

42. Boonacker E, Van Noorden CJ: The multifunctional or moonlighting protein CD26/DPPIV. Eur J Cell Biol 2003, 82:53-73

43. Takagaki Y, Koya D, Kanasaki K: Dipeptidyl peptidase-4 inhibition and renoprotection: the role of antifibrotic effects. Curr Opin Nephrol Hypertens 2017, 26:56-66

44. Lichtenberger BM, Mastrogiannaki M, Watt FM: Epidermal $\beta$-catenin activation remodels the dermis via paracrine signalling to distinct fibroblast lineages. Nat Commun 2016, 7:10537

45. Gallant-Behm CL, Olson ME, Hart DA: Cytokine and growth factor mRNA expression patterns associated with the hypercontracted, hyperpigmented healing phenotype of red duroc pigs: a model of abnormal human scar development? J Cutan Med Surg 2005, 9: 165-177

46. Ramos ML, Gragnani A, Ferreira LM: Is there an ideal animal model to study hypertrophic scarring? J Burn Care Res 2008, 29:363-368

47. Häkkinen L, Heino J, Koivisto L, Larjava H: Altered interaction of human granulation-tissue fibroblasts with fibronectin is regulated by alpha 5 beta 1 integrin. Biochim Biophys Acta 1994, 1224: $33-42$

48. Beacham DA, Amatangelo MD, Cukierman E: Preparation of extracellular matrices produced by cultured and primary fibroblasts. Curr Protoc Cell Biol 2007, Chapter 10:Unit 10.9

49. Schlagenhauff B, Klessen C, Teichmann-Dörr S, Breuninger H, Rassner G: Demonstration of proteases in basal cell carcinomas: a histochemical study using amino acid-4-methoxy-2-naphthylamides as chromogenic substrates. Cancer 1992, 70:1133-1140

50. Riikonen T, Westermarck J, Koivisto L, Broberg A, Kähäri VM, Heino J: Integrin $\alpha 2 \beta 1$ is a positive regulator of collagenase (MMP-1) and collagen $\alpha 1(\mathrm{I})$ gene expression. J Biol Chem 1995, 270: $13548-13552$

51. Nabeno M, Akahoshi F, Kishida H, Miyaguchi I, Tanaka Y, Ishii S, Kadowaki T: A comparative study of the binding modes of recently launched dipeptidyl peptidase IV inhibitors in the active site. Biochem Biophys Res Commun 2013, 434:191-196

52. Kaji K, Yoshiji H, Ikenaka Y, Noguchi R, Aihara Y, Douhara A, Moriya K, Kawaratani H, Shirai Y, Yoshii J, Yanase K, Kitade M, Namisaki T, Fukui H: Dipeptidyl peptidase-4 inhibitor attenuates hepatic fibrosis via suppression of activated hepatic stellate cell in rats. J Gastroenterol 2014, 49:481-491

53. Bustin SA, Benes V, Garson JA, Hellemans J, Huggett J, Kubista M, Mueller R, Nolan T, Pfaffl MW, Shipley GL, Vandesompele J, Wittwer CT: The MIQE guidelines: minimum information for publication of quantitative real-time PCR experiments. Clin Chem 2009, $55: 611-622$

54. Gu YR, Li MZ, Zhang K, Chen L, Jiang AA, Wang JY, Li XW: Evaluation of endogenous control genes for gene expression studies across multiple tissues and in the specific sets of fat- and muscle-type samples of the pig. J Anim Breed Genet 2011, 128:319-325

55. Liu LL, Zhao H, Ma TF, Ge F, Chen CS, Zhang YP: Identification of valid reference genes for the normalization of RT-qPCR expression studies in human breast cancer cell lines treated with and without transient transfection. PLoS One 2015, 10:e117058

56. Rieu I, Powers SJ: Real-time quantitative RT-PCR: design, calculations, and statistics. Plant Cell 2009, 21:1031-1033

57. Hinz B, Phan SH, Thannickal VJ, Prunotto M, Desmoulière A, Varga J, De Wever O, Mareel M, Gabbiani G: Recent developments in myofibroblast biology: paradigms for connective tissue remodeling. Am J Pathol 2012, 180:1340-1355

58. Gangemi EN, Gregori D, Berchialla P, Zingarelli E, Cairo M, Bollero D, Ganem J, Capocelli R, Cuccuru F, Cassano P, Risso D, Stella M: Epidemiology and risk factors for pathologic scarring after burn wounds. Arch Facial Plast Surg 2008, 10:93-102

59. Mahdavian Delavary B, van der Veer WM, Ferreira JA, Niessen FB: Formation of hypertrophic scars: evolution and susceptibility. J Plast Surg Hand Surg 2012, 46:95-101 
60. Green JA, Yamada KM: Three-dimensional microenvironments modulate fibroblast signaling responses. Adv Drug Deliv Rev 2007, 59:1293-1298

61. Yamada KM, Cukierman E: Modeling tissue morphogenesis and cancer in 3D. Cell 2007, 130:601-610

62. Iyer VR, Eisen MB, Ross DT, Schuler G, Moore T, Lee JC, Trent JM, Staudt LM, Hudson J Jr, Boguski MS, Lashkari D, Shalon D, Botstein D, Brown PO: The transcriptional program in the response of human fibroblasts to serum. Science 1999, 283:83-87

63. Laping NJ, Grygielko E, Mathur A, Butter S, Bomberger J, Tweed C, Martin W, Fornwald J, Lehr R, Harling J, Gaster L, Callahan JF, Olson BA: Inhibition of transforming growth factor (TGF)-beta1-induced extracellular matrix with a novel inhibitor of the TGF-beta type I receptor kinase activity: SB-431542. Mol Pharmacol 2002, 62:58-64

64. Penn JW, Grobbelaar AO, Rolfe KJ: The role of the TGF- $\beta$ family in wound healing, burns and scarring: a review. Int J Burns Trauma 2012, 2:18-28

65. Kennett CN, Cox SW, Eley BM: Histochemical and immunocytochemical localization of dipeptidyl peptidases II and IV in human gingiva. J Periodontol 1996, 67:846-852

66. Sorrell JM, Brinon L, Baber MA, Caplan AI: Cytokines and glucocorticoids differentially regulate APN/CD13 and DPPIV/CD26 enzyme activities in cultured human dermal fibroblasts. Arch Dermatol Res 2003, 295:160-168

67. Dufour A, Overall CM: Missing the target: matrix metalloproteinase antitargets in inflammation and cancer. Trends Pharmacol Sci 2013, $34: 233-242$

68. Horiguchi M, Ota M, Rifkin DB: Matrix control of transforming growth factor- $\beta$ function. J Biochem 2012, 152:321-329

69. Fang F, Ooka K, Bhattacharyya S, Wei J, Wu M, Du P, Lin S, Del Galdo F, Feghali-Bostwick CA, Varga J: The early growth response gene Egr2 (alias Krox20) is a novel transcriptional target of transforming growth factor- $\beta$ that is up-regulated in systemic sclerosis and mediates profibrotic responses. Am J Pathol 2011, 178:2077-2090

70. Bhattacharyya S, Fang F, Tourtellotte W, Varga J: Egr-1: new conductor for the tissue repair orchestra directs harmony (regeneration) or cacophony (fibrosis). J Pathol 2013, 229:286-297
71. Fang F, Shangguan AJ, Kelly K, Wei J, Gruner K, Ye B, Wang W, Bhattacharyya S, Hinchcliff ME, Tourtellotte WG, Varga J: Early growth response 3 (Egr-3) is induced by transforming growth factor- $\beta$ and regulates fibrogenic responses. Am J Pathol 2013, 183: 1197-1208

72. Badri KR, Yue M, Carretero OA, Aramgam SL, Cao J, Sharkady S, Kim GH, Taylor GA, Byron KL, Schuger L: Blood pressure homeostasis is maintained by a P311-TGF- $\beta$ axis. J Clin Invest 2013 , 123:4502-4512

73. Lichtman MK, Otero-Vinas M, Falanga V: Transforming growth factor beta (TGF- $\beta$ ) isoforms in wound healing and fibrosis. Wound Repair Regen 2016, 24:215-222

74. Ehrlich HP, Desmoulière A, Diegelmann RF, Cohen IK, Compton CC, Garner WL, Kapanci Y, Gabbiani G: Morphological and immunochemical differences between keloid and hypertrophic scar. Am J Pathol 1994, 145:105-113

75. Lee JY, Yang CC, Chao SC, Wong TW: Histopathological differential diagnosis of keloid and hypertrophic scar. Am J Dermatopathol 2004, 26:379-384

76. Atiyeh BS, Costagliola M, Hayek SN: Keloid or hypertrophic scar: the controversy: review of the literature. Ann Plast Surg 2005, 54: 676-680

77. Metzemaekers M, Van Damme J, Mortier A, Proost P: Regulation of chemokine activity: a focus on the role of dipeptidyl peptidase IV/CD26. Front Immunol 2016, 7:483

78. Shi S, Kanasaki K, Koya D: Linagliptin but not sitagliptin inhibited transforming growth factor- $\beta 2$-induced endothelial DPP-4 activity and the endothelial-mesenchymal transition. Biochem Biophys Res Commun 2016, 471:184-190

79. Abdullahi A, Amini-Nik S, Jeschke MG: Animal models in burn research. Cell Mol Life Sci 2014, 71:3241-3255

80. Hirsinger E, Jouve C, Dubrulle J, Pourquié O: Somite formation and patterning. Int Rev Cytol 2000, 198:1-65

81. de Hemptinne I, Gallant-Behm CL, Noack CL, Parreno J, Hart DA: Dermal fibroblasts from red Duroc and Yorkshire pigs exhibit intrinsic differences in the contraction of collagen gels. Wound Repair Regen 2008, 16:132-142 